\title{
$1 \quad$ Numerical Modeling of Spudcan Deep Penetration in Three-layer
}

\section{J. Zheng ${ }^{1}$, M. S. Hossain ${ }^{2}$ and D. Wang ${ }^{3}$}

$6 \quad{ }^{1} \mathrm{PhD}$ Student, Centre for Offshore Foundation Systems (COFS), The University of Western 7 Australia, 35 Stirling highway, Crawley, WA 6009, Tel: +61 (0)8 6488 4248, Fax: +61 (0)8 $8 \quad 6488$ 1044, Email: 21102353@student.uwa.edu.au

$9{ }^{2}$ Corresponding Author, Associate Professor, ARC DECRA Fellow, Centre for Offshore 10 Foundation Systems (COFS), The University of Western Australia, 35 Stirling highway, 11 Crawley, WA 6009, Tel: +61 (0)8 6488 7358, Fax: +61 (0)8 6488 1044, Email:

12 muhammad.hossain@uwa.edu.au

$13{ }^{3}$ Assistant Professor, Centre for Offshore Foundation Systems (COFS), The University of

14 Western Australia, 35 Stirling highway, Crawley, WA 6009, Tel: +61 (0)8 6488 3447, Fax:

$15+61$ (0)8 6488 1044, Email: dong.wang@uwa.edu.au

16

17 - Number of Words: 6830

18 - Number of Tables: 1 
Abstract: This paper reports the results from numerical modeling of spudcan deep penetration through three-layer clays. Two typical seabed strength profiles commonly encountered in the field, and identified as critical for potential punch-through failure, were considered. These include (a) uniform stiff-soft-stiff clay and (b) non-uniform clay with an interbedded stiff clay layer. 3D large deformation finite element (LDFE) analyses were carried out with and without simulating strain softening and strain rate dependency of the shear strength. The results were compared with previously published LDFE results and centrifuge test data. A detailed parametric study was undertaken, varying the relevant range of layer thicknesses (relative to the spudcan diameter), strength ratios, normalized strength and strength non-homogeneity. Punch-through and rapid leg penetration (for stiff-over-soft) and squeezing (for the reverse) were demonstrated by the penetration resistance profiles and associated soil failure mechanisms.

The results emphasized that the resistance profile from a spudcan continuous penetration in a three-layer sediment (e.g. stiff-soft-stiff) may be significantly different from the combined profiles resulted from two separate analyses on $1^{\text {st }}-2^{\text {nd }}$ layer and $2^{\text {nd }}-3^{\text {rd }}$ layer even if an appropriate depth factor was accounted for. For uniform stiff-soft-stiff clays, the presence of the bottom stiff clay layer within a short distance of 1 diameter affected spudcan bearing response in the top layer and suppressed the potential for punch-through failure (apart from rapid leg run for $\mathrm{t}_{1} / \mathrm{D}=0.75$ and $\mathrm{Sul}_{\mathrm{s}} / \mathrm{su}_{\mathrm{u}}=3$ ). A trapped soil plug beneath the advancing spudcan, following penetration of the top stiff layer, caused the bottom stiff layer to be sensed 
45 interbedded stiff layer, spudcan bearing response was dominated by squeezing (with limiting 46 squeezing depth of about $\sim 0.18 \mathrm{D}$ ) in the top soft layer and potential punch-through and rapid 47 leg run (for $\mathrm{t}_{2} / \mathrm{D} \geq 0.5$ and $\left.\mathrm{su}_{2} / \mathrm{su}_{\mathrm{s}}=2.5\right)$ in the middle and bottom layers. In contrast to ISO 48 recommendation, the soft soils in between the advancing spudcan base and the stronger layer 49 did not squeeze out completely. Instead, some of the trapped material was forced into the 50 underlying stronger layer. Punch-though distance was found to reduce significantly with 51 increasing positive strength gradient of the bottom layer.

52 CE Database subject headings: Clays; Finite element method; Flow patterns;

53 Foundations; Load bearing capacity; Offshore structures; Penetration resistance. 


\section{Introduction}

\section{Jack-up Rig and Spudcan Foundations}

Most offshore drilling in shallow to moderate water depths is performed from self-elevating jack-up rigs due to their proven flexibility, mobility and cost-effectiveness (CLAROM 1993; Bennett and Associates 2005; Randolph et al. 2005). Today's jack-ups typically consist of three independent truss legs, each attached to a large 10 to 20 m diameter spudcan. Prior to operations the legs are jacked down, eventually lifting the hull clear of the water and transferring the weight of the structure to the spudcan foundations on the seabed (Young et al. 1984). Each foundation is preloaded, by ballasting the hull, to between 50 and $100 \%$ above normal operating conditions to provide a margin of safety against failure during storm conditions (ISO 2011).

\section{Jack-up Evolution in Problematic Seabed Sediments}

Depletion of known reserves in the shallow waters of traditional hydrocarbon regions is resulting in exploration in deeper and undeveloped environments with more complex soil conditions. In emerging provinces and fields, highly layered soils are prevalent. For instance, over $75 \%$ of the case study data sets forming the basis for the InSafeJIP (2010) involved stratified seabed profiles, with interbedded layers of clay and sand displaying strong variations in shear strength. The Sunda Shelf, offshore Malaysia, Australia's Bass Strait and North-West Shelf, Gulf of Thailand, South China Sea, offshore India and Persian Gulf are particularly problematic in terms of stratigraphy and soil types (e.g. see Figure 1). Layered deposits are also encountered in the Gulf of Mexico (Menzies and Lopez 2011). 


\section{Identified Problems in Jack-up Installation}

Highly stratified soil conditions with an interbedded strong layer overlying a weak layer (Figure 1) cause significant problems during jack-up installation and preloading of the spudcans. Depending on the applied preload relative to the peak bearing capacity (which is a function of the strength ratio and the relative thickness of the layers), sudden rapid penetration of the foundation may take place. This is termed either 'rapid leg run', which is controllable by jacking capacity, or 'punch-through' failure, which signifies uncontrollable penetration over a significant depth. Despite efforts by the jack-up industry to minimize these risks, punch-through failures continue to occur at an increasing rate (Jack et al. 2007, 2013). These events may lead to buckling of the leg, effectively decommissioning the platform, or may even result in toppling of the unit (Aust 1997; Maung and Ahmad 2000; Brennan et al. 2006; Kostelnik et al. 2007; Chan et al. 2008). In this study, spudcan penetration in two typical stratified seabed strength profiles commonly encountered in the field, and which are identified as critical for potential punch-through, are explored. The strength profiles include (i) uniform stiff-soft-stiff clay and (ii) non-uniform clay with an interbedded stiff layer, with typical examples shown in Figure 1.

\section{Previous Work and Objective of Present Study}

A number of investigations have been carried out on foundation response in two-layer clays through experimental work and finite element analyses, such as on stiff-over-soft clay (Brown and Meyerhof 1969; Wang and Carter 2002; Edwards and Potts 2004; Merifield and Nguyen 2006; Hossain and Randolph 2010a, b; Hossain et al. 2011; Tho et al. 2012) and in the reverse (Meyerhof and Chaplin 1953; Brown and Meyerhof 1969; Merifield and Nguyen 2006). Brown and Meyerhof (1969) conducted model tests at $1 \mathrm{~g}$ using a circular footing sitting on the surface of layered soils. Small strain finite element (FE) analyses on surface footings were 
undertaken by Edwards and Potts (2004) and Merifield and Nguyen (2006). Continuous penetration of plane strain and circular foundations were simulated by Wang and Carter (2002) using a large deformation finite element (LDFE) method, the RITSS (remeshing and interpolation technique with small strain; $\mathrm{Hu}$ and Randolph 1998) approach coupled with locally developed FE package AFENA (Carter and Balaam 1990).

Spudcan penetration on stiff-over-soft clays has been addressed more recently. The results from centrifuge model tests and large deformation finite element (LDFE) analyses (using RITSS/AFENA) were reported by Hossain and Randolph (2010a, b), while those from LDFE analyses, using the Coupled Eulerian-Lagrangian (CEL) approach in Abaqus/Explicit, were presented by Tho et al. (2012). They all presented the results in terms of load penetration response and/or of non-dimensional bearing capacity factors.

For spudcan penetration on stiff-over-soft clay, Hossain and Randolph (2010a, 2010b) have revealed the failure mechanisms. Severe punch-through was associated with vertically downward soil displacements beneath the spudcan in the upper layer and consequently a soil plug with the shape of an inverted truncated cone was eventually forced down into the underlying soft layer. Punch-through occurred for all cases where the strength ratio, Su1/su2, was greater than or equal to 1.67 , with the severity being greater the higher the strength ratio, and the thicker the upper layer, but reducing as the strength gradient in the lower layer increased. Design expressions have been developed by Brown and Meyerhof (1969) and Hossain and Randolph (2009c).

For spudcan penetration on soft-over-stiff clay, Merifield and Nguyen (2006) performed small strain finite element analyses for wished-in-place circular footings. The soft clay between the footing and the underlying strong layer tended to be squeezed out, but yielding also occurred well into the strong layer. From centrifuge model tests, Hossain et al. (2011) highlighted that a layer of soft clay from the $1^{\text {st }}$ layer may be trapped at the base of the spudcan while 
124 penetrating into the $2^{\text {nd }}$ (stiff) layer. However, the design approach in ISO guidelines 19905-1

125 (ISO 2011) is based on bearing capacity factors proposed by Meyerhof and Chaplin (1953)

126 assuming that the cylindrical clay block between parallel rigid plates is squeezed out

127 completely.

128 To date, no research has been published that investigates penetration of spudcan foundations

129 in multi-layer clay profiles. As such, the recently finalized version of ISO guidelines 19905-1

130 (ISO 2011; Wong et al. 2012) and completed joint industry project 'InSafeJIP' (InSafeJIP

131 2010) provide no recommendation for assessing spudcan penetration in more general multi-

132 layer soils apart from noting that a so called 'bottom-up approach' can be used combining the

133 squeezing (for stiff over soft layering) and punch-through (for the reverse) criteria for two

134 layer systems.

135 In this study, an extensive investigation was carried out through centrifuge model tests and 3D

136 LDFE analyses on vertical penetration of spudcan foundations in general multi-layer fine grained

137 sediments. The results from centrifuge model tests were reported by Hossain et al. (2011) and

138 Hossain (2014). This paper provides results from parametric LDFE analyses considering a

139 simple elastic-perfectly plastic Tresca soil model, giving penetration resistance profiles and

140 soil failure mechanisms. Analyses were also performed using a modified Tresca model,

141 allowing strain softening, and incorporating strain rate dependency of the undrained shear

142 strength, for comparison. The difference between combining two-layer soft-over-stiff and

143 stiff-over-soft systems (bottom-up approach) and a spudcan continuous penetration in a three-

144 layer soil is highlighted. 


\section{Numerical Analysis}

\section{Geometry and Parameters}

This study has considered a circular spudcan of diameter D, penetrating into a three-layer clay deposit as illustrated schematically in Figure 2, where the middle layer with uniform undrained shear strength su2 and thickness $t_{2}$ is sandwiched by the top layer of non-uniform undrained shear strength $\mathrm{su}_{1}=\mathrm{sum}_{\mathrm{u}}+\mathrm{k}_{1} \mathrm{Z}$ and thickness $\mathrm{t}_{1}$; and the bottom layer of non-uniform undrained shear strength $\mathrm{su}_{3}=\mathrm{Su}_{\mathrm{us}}+\mathrm{k}_{3}\left(\mathrm{z}-\mathrm{t}_{1}-\mathrm{t}_{2}\right)$, with undrained shear strength at the $2^{\text {nd }}-3^{\text {rd }}$ layer interface Su3s, and (nominally) infinite depth. Suls is the undrained shear strength at the $1^{\text {st }}-2^{\text {nd }}$ layer interface (i.e. $\left.\mathrm{suls}_{\mathrm{s}}=\mathrm{sum}_{\mathrm{m}}+\mathrm{k}_{1} \mathrm{t}_{1}\right)$. Analyses were undertaken for a spudcan with a $13^{\circ}$ shallow conical underside profile (included angle of $154^{\circ}$ ) and a $76^{\circ}$ protruding spigot of height $0.14 \mathrm{D}$ (see Figure 2). The spudcan shape is similar to the spudcans of the "Marathon LeTourneau Design, Class 82-SDC” jack-up rig, as illustrated by Menzies and Roper (2008).

The numerical program concentrated on simulating simplified strength profiles from reported case histories (e.g. InSafeJIP 2010) with normalized soil properties and layer geometries. In addition, in order to select realistic soil parameters for parametric study, a survey was carried out through offshore geotechnical characterization reports. The three-layer geometries considered here are commonly encountered in the Gulf of Thailand and Sunda Shelf, including Java Sea, as reported by Castleberry II and Prebaharan (1985), Handidjaja et al. (2004), Kostelnik et al. (2007), Chan et al. (2008) and InSafeJIP (2010).

For uniform three-layer clay sediments, the undrained shear strength of stiff clay ranges from 40 to $120 \mathrm{kPa}$, while that of soft clay varies between 10 and $40 \mathrm{kPa}$. For non-uniform clay deposit with an interbedded uniform clay layer, typical undrained shear strength of the middle layer can be found as Su2 $=40$ to $75 \mathrm{kPa}$, and those of the $1^{\text {st }}$ and $3^{\text {rd }}$ layers as Sum $=0$ to $15 \mathrm{kPa}$ and $\mathrm{Su} 3 \mathrm{~s}=30$ to $50 \mathrm{kPa}$, respectively, increasing with depth with a gradient $\mathrm{k}_{1}=\mathrm{k}_{3}=1 \sim 3$ 
$170 \mathrm{kPa} / \mathrm{m}$. The effective unit weight $\gamma^{\prime}$ for a three-layer soil system has a typical range of 6.5 to

$1718.5 \mathrm{kN} / \mathrm{m}^{3}$. The (equivalent area) diameter of modern spudcan foundations ranges from 10 to

$17220 \mathrm{~m}$ (Menzies and Roper 2008). The selected parameters for this study are assembled in

173 Table 1, encompassing a range of practical interest in terms of the likelihood of rapid leg run

174 or punch-through.

\section{Analysis Details}

176 The LDFE analyses were performed using the CEL approach in Abaqus/Explicit. The feature

177 of 'fixed' Eulerian mesh and the contact between the Eulerian and Lagrangian materials allow

178 for effective application of the CEL approach in large deformation geotechnical problems,

179 circumventing some corresponding problems such as severe distortion of mesh associated

180 with the progress of an object penetration. Other applications of this technique include cone

181 and strip footing penetration in cohesive soils (Qiu and Grabe 2011), spudcan penetration in

182 single and two-layer clays (Tho et al. 2012), and spudcan penetration in sand overlying clay

183 (Qiu and Henke 2011; Qiu and Grabe 2012).

184 Current CEL function is only for three-dimensional elements. For the parametric studies, only

185 a quarter sector of the domain was involved in the analyses accounting for the symmetry

186 inherent, as shown in Figure 3. The soil domain was chosen as 6.25D in horizontal and 11.7D

187 in depth, which was testified as sufficiently large to avoid boundary effect. Similar domain

188 sizes were considered by Qiu and Henke (2011) and Tho et al. (2012) in spudcan continuous

189 penetration analysis. The spudcan was modeled as a rigid Lagrangian body and the soil-

190 spudcan interface as fully rough unless otherwise stated. The soil and spudcan foundation

191 were discretized using Eulerian hexahedral elements of type EC3D8R and continuum

192 elements of types C3D8R (hexahedron) and C3D6 (triangular prism), respectively. These

193 element types are linear elements with reduced integration and hourglass control. The soil 
194

195

layers were included in the Eulerian mesh, and they underlay an initially 'void' layer to accommodate the soil heave resulting from spudcan penetration.

The soil was modeled as a linear elastic-perfectly plastic material obeying a Tresca yield criterion. This simple soil model provided satisfactory results in terms of ultimate penetration resistance in comparison to theoretical solutions for various problems such as spudcan (Hossain and Randolph 2009b), circular and strip footings (Wang and Carter 2002) and ball and cone (Lu et al. 2004; Zhou et al. 2012) penetration in clay and uplift of plate anchors (Thorne et al. 2004). The elastic parameters for clay were considered to be independent of stresses and a uniform stiffness ratio of $\mathrm{E} / \mathrm{s}_{\mathrm{u}}=200$ was taken throughout the clay profile. The stiffness ratio is within the range commonly adopted for soft clays, but the precise value has negligible effect on the results presented. Considering relatively fast penetration of spudcans in the field, all the analyses simulated undrained conditions and adopted a Poisson's ratio $v=$ 0.49 (sufficiently high to give minimal volumetric strains, while maintaining numerical stability). The geostatic stress conditions were modeled using $\mathrm{K}_{0}=1$, as the stable penetration resistance (once backflow is fully established) has been found to be unaffected by the value of $\mathrm{K}_{0}$ (Zhou and Randolph 2009).

Typical computation times on a fast desktop computer were about $36 \sim 48 \mathrm{~h}$ for a spudcan penetration of three diameters. This is slightly longer than the time required for undertaking an axisymmetric analysis using e.g. RITSS/AFENA. However, 3D LDFE analyses will provide with the long term opportunity for carrying out further analyses under operational loadings and for spudcan penetration near an existing footprint.

\section{Incorporation of Combined Effect of Strain Rate and Softening}

Following Einav and Randolph (2005) and Zhou and Randolph (2007), the Tresca soil model was extended to take the combined effects of rate dependency and progressive softening into 
218

219

220

$\mathrm{s}_{\mathrm{uc}}=\left[1+\mu \log \left(\frac{\operatorname{Max}\left(|\dot{\gamma}|, \dot{\gamma}_{\text {ref }}\right)}{\dot{\gamma}_{\text {ref }}}\right)\right]\left[\delta_{\text {rem }}+\left(1-\delta_{\text {rem }}\right) \mathrm{e}^{-3 \xi / \xi_{95}}\right] \mathrm{s}_{\mathrm{u}}$

221 where suc is the undrained shear strength considering rate-dependency and strain-softening 222 and $\mathrm{su}$ is the intact undrained shear strength measured at the reference shear strain rate prior to any softening.

The first bracketed term augments the strength according to the shear strain rate relative to a reference value, $\dot{\gamma}_{\text {ref }}$, which was considered as $1.5 \% / \mathrm{h}$ corresponding to the typical strain rate 226 in triaxial tests (Erbrich 2005; Lunne et al. 2006). The augment of shear strength follows a 227 logarithmic law with rate parameter $\mu$ taken as 0.1 for spudcan foundations (Low et al. 2008). 228 The spudcan penetration rate in the field was taken as $2 \mathrm{~m} /$ hour.

229 The second part of Equation 1 models the degradation of strength according to an exponential 230 function of cumulative shear strain, $\xi$, from the intact condition to a fully remolded ratio, $\delta_{\text {rem }}$ $231\left(=1 / \mathrm{S}_{\mathrm{t}}\right.$, i.e. inverse of sensitivity $\left.\mathrm{S}_{\mathrm{t}}\right)$. The relative ductility is controlled by the parameter, $\xi_{95}$, 232 which represents the cumulative shear strain required for $95 \%$ remolding. A typical value of $233 \xi_{95}=12$ (i.e., 1200\% shear strain; Randolph 2004) was used. Further details can be found in 234 Hossain and Randolph (2009a) and Zheng et al. (2013). 


\section{Validation of Results}

The load-penetration responses are presented in terms of net bearing pressure, qnet, normalized by the shear strength intercept at the $2^{\text {nd }}-3^{\text {rd }}$ layer interface (su3s), as a function of normalized penetration depth, $d / D$, with qnet calculated by deducting spudcan buoyancy as

$$
\mathrm{q}_{\mathrm{net}}=\frac{\mathrm{P}}{\mathrm{A}}-\gamma^{\prime} \frac{\mathrm{V}}{\mathrm{A}}
$$

where $\mathrm{P}$ is the penetration resistance (i.e. the total vertical reaction force provided by the soil), $\mathrm{V}$ is the volume of the embedded spudcan including shaft and $\mathrm{A}$ is the largest plan area of the spudcan. Calculation of $\mathrm{q}_{\text {net }}$ using Equation 2 and normalization using su3s yield a deep (after backflow) bearing capacity factor in the $3^{\text {rd }}$ layer of uniform undrained shear strength and allowed to maintain the form of the resistance profile for all soil profiles considered. In all the response curves, the spudcan penetration is plotted relative to the depth of the lowest maximum diameter of the spudcan below the original ground surface (i.e. $d / D=0$, see Figure 2).

\section{Validation against Results from LDFE Analyses Using RITSS}

Validation exercise was carried out against existing results from LDFE analyses and centrifuge tests. As noted previously, Wang and Carter (2002) and Hossain and Randolph (2010b) undertook axisymmetric LDFE analyses using the RITSS coupled with AFENA. To compare with their work, analyses were performed for uniform two-layer $\left(\mathrm{k}_{1}=\mathrm{k}_{2}=0\right)$ stiffover-soft clays, with and without soil weight, and without accounting for the effects of strain softening and rate dependency.

Figure $4 \mathrm{a}$ shows the normalized net bearing pressure, $\mathrm{q}_{\mathrm{net} 0} / \mathrm{su2}$ (where the subscript 0 denotes weightless soil) for a smooth-based circular flat footing penetrating into layered soils with $\mathrm{t}_{1} / \mathrm{D}=1$ and $\mathrm{Su1s} / \mathrm{Su2}=1,2$ and 10 (Group I, Table 1$)$. The figure also includes results reported 
by Wang and Carter (2002). Both sets of results are in excellent agreement with variations mostly less than $5 \%$, confirming the accuracy of the CEL results.

For spudcan penetration, LDFE analyses were performed on weighty stiff-over-soft clay with $\mathrm{t}_{1} / \mathrm{D}=0.5$ and $\mathrm{Su1s} / \mathrm{su2}=1.25,1.67,2.5$ and 5 (Group II, Table 1). The normalized penetration resistances are plotted in Figure $4 \mathrm{~b}$ for comparison with the results reported by Hossain and Randolph (2010b). Again excellent agreement can be seen in terms of both soil backflow depth and load-penetration response with variations in both regards mostly less than $5 \%$.

\section{Validation against Centrifuge Test Data}

267 Comparisons are presented here between two of the model tests (Tests T6 and T8, Table 2 of 268 Hossain et al. 2011) and LDFE simulations (Group III, Table 1). Tests modeled a spudcan of 269 prototype diameter $12 \mathrm{~m}$ penetrating three-layer deposits with $\mathrm{t}_{1} / \mathrm{D}=0.38, \mathrm{t}_{2} / \mathrm{D}=0.58$ (for T6) 270 and $t_{1} / D=0.42, t_{2} / D=0.5$ (for $T 8$ ). The undrained shear strength profiles were idealized as $271 \mathrm{Su}_{1}=\mathrm{Su}_{3}=2+0.6 \mathrm{z} \mathrm{kPa}, \mathrm{Su}_{2}=23 \mathrm{kPa}\left(\right.$ for T6) and $\mathrm{su} 1=16+0.8 \mathrm{z} \mathrm{kPa}, \mathrm{su}_{2}=11 \mathrm{kPa}, \mathrm{su} 3=33$

$272 \mathrm{kPa}$ (for T8). The average clay effective unit weights were 7.5 and $7.3 \mathrm{kN} / \mathrm{m}^{3}$ for the top layer 273 and lower layers respectively. Analyses were performed for the above cases for idealized 274 Tresca materials (without considering softening and rate-dependency), and also with strain 275 softening and rate dependency taken into account $\left(\delta_{\text {rem }}=0.36, \mu=0\right.$ and $0.1, \xi_{95}=12, \dot{\gamma}_{\text {ref }}=$ $276 \quad 1.5 \% / \mathrm{h})$.

277 Figures $5 \mathrm{a}$ and $5 \mathrm{~b}$ show the load-penetration responses from the LDFE analyses and 278 centrifuge tests. For rate-independent, perfectly plastic (referred to as 'ideal') soil, the LDFE 279 result is in good agreement with the centrifuge test data at shallow penetration depths in the 280 top layer and lies above (around 15 20\% higher) at deep penetration depths in the $2^{\text {nd }}$ and $3^{\text {rd }}$ 281 layers. Taking strain softening and strain rate effects into account, the curves diverge 282 gradually with the progress of penetration, and eventually closely match the one from the 
centrifuge test. Furthermore, the form of the penetration resistance profile and the likelihood of punch-through are better reflected in the curves for strain softened, rate dependent soils.

\section{Results and Discussion}

The soil failure mechanisms and hence the bearing capacity profiles of spudcan foundations on layered clays are affected mainly by the following factors: (a) the strength ratios between adjacent layers, $\mathrm{Su}_{\mathrm{s}} / \mathrm{Su2}$ and $\mathrm{Su2} / \mathrm{Su3s}$; (b) the thickness ratios of soil layers relative to the spudcan diameter, $\mathrm{t}_{1} / \mathrm{D}$ and $\mathrm{t}_{2} / \mathrm{D}$; (c) the normalized undrained shear strength of the bottom layer, Su3s $/ \gamma^{\prime} \mathrm{D}$; (d) the strength gradient of the bottom layer, denoted by the non-homogeneity factor, $\mathrm{k}_{3} \mathrm{D} / \mathrm{su3s}$. In the following sub-sections, critical soil failure mechanisms for the two soil profiles investigated are first presented. The penetration resistance profiles for ideal soil are then discussed in relation to the various factors, and finally the influence of accounting for softening and rate dependency is highlighted. For selecting computational aspects, routine preliminary simulations were carried out, varying the element size around the spudcan, $h_{\min } / D$, and penetration velocity of the spudcan, $\mathrm{Vsp}$. Balancing the computational effort and accuracy of the computed results, and also complying with existing studies (e.g. Tho et al. 2012), $\mathrm{h}_{\min } / \mathrm{D}=0.05$ and $\mathrm{v}_{\mathrm{sp}}=0.1 \mathrm{~m} / \mathrm{s}$ were adopted for the parametric study.

\section{Soil Failure Mechanisms}

As noted previously, a spudcan penetration in three-layer stiff-soft-stiff clay deposits is usually treated combining spudcan penetration in two-layer stiff-over-soft and the reverse deposits. This approach essentially neglects the influence of the overlying layer, which is highlighted below. 
The soil flow mechanisms observed are discussed below, linking these directly to the profile of penetration resistance. Figure 6 a depicts the soil flow mechanism at a spudcan penetration depth of $\mathrm{d} / \mathrm{D}=0.48$ (near the $1^{\text {st }}-2^{\text {nd }}$ layer interface) in a deposit with $\mathrm{su1}=\mathrm{su1s}=120 \mathrm{kPa}$, Su2 $=40 \mathrm{kPa}, \mathrm{Su}_{3}=\mathrm{su}_{3 \mathrm{~s}}=75 \mathrm{kPa}$ and $\mathrm{t}_{1} / \mathrm{D}=\mathrm{t}_{2} / \mathrm{D}=0.5($ Group IV, Table 1$)$. A somewhat rapid leg run occurs in the upper layer (see the corresponding resistance profile later in Figure 7b). A soil plug from the upper stiff layer is trapped beneath the advancing spudcan and forced down into the $2^{\text {nd }}$ layer (see Figure $6 \mathrm{a}$ ). The advancement of the spudcan with the trapped soil plug at the base results in early squeezing of soil sensing the $3^{\text {rd }}$ layer, as shown in Figure 6a. The resistance profile therefore rises in the middle soft layer without tending to reduce.

For spudcan penetration in soft-over-stiff clay, it is assumed in the ISO guideline (ISO 2011) that the soil between the advancing spudcan and the stiff clay layer squeezes out completely. Figure $6 b$ shows the soil flow mechanism at a spudcan penetration depth of $d / D=0.55$ (after penetrating into the $3^{\text {rd }}$ layer $)$ in a deposit with $\mathrm{Su} 1=2+2 \mathrm{z} \mathrm{kPa}, \mathrm{Su} 2=75 \mathrm{kPa}, \mathrm{Su} 3=30+1(\mathrm{z}-$ $\left.\mathrm{t}_{1}-\mathrm{t}_{2}\right) \mathrm{kPa}$ and $\mathrm{t}_{1} / \mathrm{D}=\mathrm{t}_{2} / \mathrm{D}=0.25$ (Group $\mathrm{V}$, Table 1$)$. Clearly, a layer of soft clay from the $1^{\text {st }}$ layer is trapped beneath the spudcan base and penetrated into the $3^{\text {rd }}$ soft layer, enhancing the height of the soil plug and hence the corresponding frictional resistance.

\section{Penetration Resistance: Uniform Clay with an Interbedded Soft Clay Layer}

\section{Effect of strength ratio (Su1s/Su2)}

In an attempt to explore the effect of strength ratio $\mathrm{Suls} / \mathrm{Su} 2$ on the form of the penetration resistance profile, the results of various top layer strength $\mathrm{Su}_{1}=\mathrm{suls}_{\mathrm{s}}=50,80$ and $120 \mathrm{kPa}$ are plotted in Figures $7 \mathrm{a} \sim 7 \mathrm{c}$ for thickness ratio $\mathrm{t}_{1} / \mathrm{D}=0.75,0.5$ and 0.25 respectively. The strengths of the $2^{\text {nd }}$ and $3^{\text {rd }}$ layers are constant as $\mathrm{su2}=40 \mathrm{kPa}$ and $\mathrm{su} 3=\mathrm{su3s}=75 \mathrm{kPa}(\mathrm{su2} / \mathrm{su3s}=$ 0.53 ) with the normalized strength of the bottom layer su3s $/ \gamma^{\prime} \mathrm{D}=0.78$ (Group IV, Table 1 ). 
328 For given thickness ratios of $t_{1} / D$ and $t_{2} / D$, the bearing pressure increases as the strength of

329 the top layer and (hence) the strength ratio $\mathrm{Su}_{\mathrm{u}} / \mathrm{S}_{\mathrm{u} 2}$ increase. This is because the proportion of

330 domination of the top strong layer increases and that of the middle soft layer decreases. This

331 influence becomes more profound with increasing thickness of the top layer, $t_{1} / D$, and/or 332 reducing that of the $2^{\text {nd }}$ layer, $\mathrm{t}_{2} / \mathrm{D}$.

333 The critical depth of soil backflow above the advancing spudcan (which can also be taken as

334 the limiting cavity depth) is also affected by the strength ratio although, in all the analyses 335 performed in Group IV (Table 1), backflow occurs in the middle or bottom layer. A stronger 336 top layer strength has delayed soil backflow, with more downward soil deformation and 337 forming thicker soil plug at the base of the advancing spudcan.

338 For all cases, no reduction in penetration resistance profile forming a local peak is evident.

339 The results for identical strength ratio, Su1s/Su2, and thickness ratio, $\mathrm{t}_{1} / \mathrm{D}$, but in the absence of 340 the $3^{\text {rd }}$ layer (i.e. on two-layer stiff-over-soft clay deposits) are also included in Figures $7 \mathrm{a}$ and $3417 \mathrm{~b}$ for comparison. In contrast to the results for three-layer sediments, a reduction in bearing 342 resistance profile occurs for stiff-over-soft clay deposits, which is consistent with Hossain and 343 Randolph (2010a, 2010b). This indicates that, for the cases investigated in this study, 344 spudcans sense the influence of the bottom strong layer while penetrating in the top layer. 345 This influence becomes more profound as the thickness of the middle layer reduces. In terms 346 of soil backflow, the presence of the third stiff layer squeezes the soil underneath the spudcan 347 and thus reduces the depth of soil backflow.

348 In addition, the penetration resistance profiles from spudcan penetration on two-layer soft349 over-stiff clay (i.e. Su2 overlying su3 with the absence of the $1^{\text {st }}$ layer; $\mathrm{Su} 2=40 \mathrm{kPa}$, Su3s $=75$ $\left.350 \mathrm{kPa}, \mathrm{t}_{2} / \mathrm{D}=0.25\right)$ are also included in Figure $7 \mathrm{a}$ starting from the $1^{\text {st }}-2^{\text {nd }}$ layer interface, with 351 and without adding a depth factor of 0.9 (i.e. $1+0.2 \mathrm{t}_{1} / \mathrm{D}$ following ISO 2011) to the original 
normalized net bearing pressure. It can be seen that the penetration resistance profile

combining the results on two-layer stiff-over-soft and soft-over-stiff clay deposits produces a different form, with significantly lower bearing resistance, compared to the one from continuous penetration analysis on three-layer stiff-soft-stiff clay deposit.

\section{Effect of thickness ratios ( $t_{1} / D$ and $\left.t_{2} / D\right)$}

In order to explore the effect of thickness ratios on the form of load-penetration response, the profiles of $\mathrm{t}_{2} / \mathrm{t}_{1}=0.33,1.0$ and 3.0 are plotted in Figures $8 \mathrm{a} \sim 8 \mathrm{c}$, but keeping $\left(\mathrm{t}_{1}+\mathrm{t}_{2}\right) / \mathrm{D}=1.0$, with various strengths of the top layer of $\mathrm{Sul}=\mathrm{Suls}=120,80$ and $50 \mathrm{kPa}$ respectively (Group IV, Table 1). Again, the strengths of the $2^{\text {nd }}$ and $3^{\text {rd }}$ layers were constant as Su2 $=40 \mathrm{kPa}$ and $\mathrm{su}_{3}=\mathrm{su} 3 \mathrm{~s}=75 \mathrm{kPa}\left(\mathrm{su} 2_{2} / \mathrm{su} 3 \mathrm{~s}=0.53\right)$.

The effect of thickness ratios becomes more profound as $\mathrm{sul}_{\mathrm{s}} / \mathrm{su}_{\mathrm{u} 2}$ increases or the difference of 363 the undrained shear strengths between $1^{\text {st }}$ and $2^{\text {nd }}$ layer increases. For instance, Figure $8 \mathrm{a}$ 364 shows the penetration resistance profiles and soil flow mechanisms for $\mathrm{Su}_{1 \mathrm{~s}} / \mathrm{Su}_{2}=3(\mathrm{su1s}=120$ $365 \mathrm{kPa}, \mathrm{Su} 2=40 \mathrm{kPa}, \mathrm{Su3s}=75 \mathrm{kPa}$ ). The depth of soil backflow and the bearing pressure increase 366 with increasing $t_{1} / D$. When the spudcan was at the $2^{\text {nd }}-3^{\text {rd }}$ layer interface, a soil plug was 367 forced down into the bottom layer (see inserts of Figure 8a). The trapped plug comprised 368 materials from both $1^{\text {st }}$ stiff layer and $2^{\text {nd }}$ soft layer. With increasing $t_{1} / D$, more soil from the $3691^{\text {st }}$ stiff layer was trapped underneath the spudcan, while the quantity of the trapped soil from 370 the $2^{\text {nd }}$ soft layer was nearly consistent regardless of the thickness of that layer $\left(t_{2} / D\right)$, forming 371 thicker soil plug. Furthermore, as all the curves tend to approach the steady ultimate 372 resistance corresponding to the bottom layer, with increasing thickness ratio ( $\left.t_{1} / \mathrm{D}\right)$, the 373 resistance profile becomes stiffer showing greater tendency of occurring rapid leg run.

374 For $\mathrm{Su}_{1 \mathrm{~s}} / \mathrm{Su}_{2}=1.25\left(\mathrm{su1s}=50 \mathrm{kPa}, \mathrm{Su}_{2}=40 \mathrm{kPa}, \mathrm{Su}_{3 \mathrm{~s}}=75 \mathrm{kPa}\right.$; Figure $\left.8 \mathrm{c}\right)$, all curves somewhat 375 merge together with negligible effect of thickness ratios. This indicates that, as the difference 
between the strengths of the $1^{\text {st }}$ layer and $2^{\text {nd }}$ layer is small, the three-layer stiff-soft-stiff clay profile has turned to two-layer soft-over-stiff clay profile. As such, squeezing mechanism dominates the behavior with the proximity to the bottom layer.

For the cases just discussed, the total thickness of the first two layers were kept constant as ( $\mathrm{t}_{1}$ $\left.+t_{2}\right) / D=1.0$. An analysis was also carried out for $t_{1} / D=t_{2} / D=0.75$ (i.e. $\left(t_{1}+t_{2}\right) / D=1.5$ ) with strength ratio $\mathrm{Su}_{1 \mathrm{~s}} / \mathrm{Su} 2=3\left(\mathrm{Su} 1 \mathrm{~s}=120 \mathrm{kPa}, \mathrm{Su} 2=40 \mathrm{kPa}, \mathrm{Su}_{\mathrm{s}}=75 \mathrm{kPa}\right)$. Figure 9 shows the result along with the curves for $t_{1} / D=0.75, t_{2} / D=0.25$ and $t_{1} / D=0.25, t_{2} / D=0.75$ for comparison. For identical $t_{2} / D$, a thicker $1^{\text {st }}$ stiff layer allowed for developing the capacity of that layer and, for identical $t_{1} / D$, a thicker middle soft layer allowed for reducing the resistance back to the capacity of the middle layer as well as attracting the soil deformation avoiding the influence of the bottom strong layer (up to some extent). The resultant is that the profile for $t_{1} / D=t_{2} / D=0.75$ is bracketed by the curves for $t_{1} / D=0.75, t_{2} / D=0.25$ and $t_{1} / D=$ $0.25, \mathrm{t}_{2} / \mathrm{D}=0.75$ in the $1^{\text {st }}$ layer and shows a potential for punch-through at $\mathrm{d} / \mathrm{D}=0.25$.

The results from numerical analysis of a rough spudcan penetration in uniform clays with undrained shear strength of su2 and su3 together with the plasticity solutions (Martin and Randolph 2001) for a buried plate (both smooth and rough) in clay are also included in Figures 7 9 for comparison. It is apparent that the thickness of the middle layer of up to $t_{2} / D$ $=0.75$ was not sufficient for reducing the response back to the profile for uniform clay with strength $=$ Su2, although they tend to do so for lower su1s/Su2 and higher $t_{2} / D$. In the bottom layer, all curves converge and tend to merge together with the profile for uniform clay with strength $=$ Su3. In some cases slightly higher resistance was resulted due to the additional frictional resistance mobilized around the periphery of the trapped soil plug. The limiting normalized bearing resistance in the bottom layer (without the effect of the soil plug) is $\sim 3 \%$ lower than the exact plasticity solution for a rough-based buried plate (Martin and Randolph 2001). 


\section{Effect of normalized strengths (su2/ $\gamma^{\prime} D$ and $\left.s_{u 3 s} / \gamma^{\prime} D\right)$}

402

403

404

In order to explore the effect of normalized strength on spudcan bearing behavior, two curves for $\mathrm{su} 2 / \gamma^{\prime} \mathrm{D}=0.083, \mathrm{su} 3 \mathrm{~s}_{\mathrm{s}} / \gamma^{\prime} \mathrm{D}=0.16\left(\mathrm{su}_{1 \mathrm{~s}}=24 \mathrm{kPa}, \mathrm{su}_{2}=8 \mathrm{kPa}, \mathrm{su}_{3}=15 \mathrm{kPa}\right)$ and $\mathrm{su} 2 / \gamma^{\prime} \mathrm{D}=0.42$, $\mathrm{su3s}_{\mathrm{s}} / \gamma^{\prime} \mathrm{D}=0.78\left(\mathrm{su}_{1 \mathrm{~s}}=120 \mathrm{kPa}, \mathrm{su}_{2}=40 \mathrm{kPa}, \mathrm{su3s}=75 \mathrm{kPa}\right)$, with all normalized parameters consistent $\left(\mathrm{Su}_{1 \mathrm{~s}} / \mathrm{Su} 2=3, \mathrm{Su}_{2} / \mathrm{Su}_{3 \mathrm{~s}}=0.53, \mathrm{t}_{1} / \mathrm{D}=\mathrm{t}_{2} / \mathrm{D}=0.75\right.$; see Group IV, Table 1$)$, are displayed in Figure 10. The form of these two resistance profiles is completely different. For $\mathrm{Su} 2 / \gamma^{\prime} \mathrm{D}=0.42$, su3s $/ \gamma^{\prime} \mathrm{D}=0.78$, as discussed previously, the curve shows a potential for rapid leg run in the top layer, followed by rises monotonically with depth. By contrast, for $\mathrm{Su} 2 / \gamma^{\prime} \mathrm{D}=$ 0.083 , su3s $/ \gamma^{\prime} \mathrm{D}=0.16$, i.e. for significantly lower normalized undrained shear strengths, the penetration resistance profile rises monotonically with depth in the $1^{\text {st }}$ stiff layer. It drops sharply forming a local peak in the middle soft layer with the initiation of soil backflow. This may lead to a punch-through failure in the field during installation of jack-ups in similar sediments. This is consistent with the finding reported by Hossain and Randolph (2010b) although for stiff-over-soft clays.

\section{Effect of accounting for strain rate and softening}

A comparison in terms of the form of the penetration resistance profile with $\left(\delta_{\text {rem }}=0.3, \mu=\right.$

$0.1, \xi_{95}=12, \dot{\gamma}_{\text {ref }}=1.5 \% / \mathrm{h}$ ) and without accounting for strain rate and softening effects are shown in Figure $11\left(\mathrm{su1s}=50\right.$ and $\left.120 \mathrm{kPa}, \mathrm{su}_{2}=40 \mathrm{kPa}, \mathrm{Su} 3 \mathrm{~s}=75 \mathrm{kPa}\right)$. It may be seen that the profiles for strain softened, rate dependent soil exhibit potential for rapid leg run in the $2^{\text {nd }}$ layer. As discussed previously, negligible or no rapid leg run occurs for ideal soil. In addition, bearing resistance is around $17 \%$ lower particularly at deep penetration depths. 
423

424

425

426

427

428

429

430

431

433

434

\section{Penetration Resistance: Non-uniform Clay with an Interbedded Stiff Clay Layer}

In the analyses on non-uniform clay with an interbedded stiff clay layer, the strength of the stiff $\left(2^{\text {nd }}\right.$ ) layer (for Group V, Table 1) and the degree of non-homogeneity of the $3^{\text {rd }}$ layer (for Group VI, Table 1) were varied.

\section{Effect of strength ratio (su2/su3s)}

To demonstrate the effect of the $2^{\text {nd }}$ layer strength or strength ratio $\mathrm{Su} / \mathrm{Su3s}$ on the form of the penetration resistance profile, Figures $12 \mathrm{a} \sim 12 \mathrm{c}$ are plotted for $\mathrm{Su} / \mathrm{Su} 3 \mathrm{~s}=1.33$ and 2.5 , with the thickness ratios $t_{1} / D=0.25$ and $t_{2} / D=0.25,0.5$ and 0.75 , respectively. The strength nonhomogeneity factor for the top and bottom layers are $\mathrm{k}_{1} \mathrm{D} / \mathrm{sum}=12$ and $\mathrm{k} 3 \mathrm{D} / \mathrm{su3s}_{\mathrm{s}}=0.4(\mathrm{su1}=2$ $+2 \mathrm{z} \mathrm{kPa}, \mathrm{Su} 3=30+1\left(\mathrm{z}-\mathrm{t}_{1}-\mathrm{t}_{2}\right) \mathrm{kPa}$; see Group V, Table 1). In the top layer, squeezing dominates the response due to the effect of significantly stiffer (strength ratio of $\mathrm{Su} 1 \mathrm{~s} / \mathrm{Su}_{2}=$ 0.11 0.2; as also described by Hossain et al. (2011) and Hossain 2014) and relatively thicker (thickness ratio of $\left.\mathrm{t}_{2} / \mathrm{D}=0.25 \sim 0.75\right) 2^{\text {nd }}$ layer.

It is of interest to identify the depth range above the strong layer where squeezing effects start to increase the penetration resistance (defined as limiting squeezing depth). This limiting squeezing depth is a function of various factors such as the strength ratio between the two layers and whether a plug is being carried down with the advancing spudcan (as was what happened for stiff-soft-stiff clay; see the soil flow mechanisms in Figures 6a and 8c). For all cases with $\mathrm{Su}_{1 \mathrm{~s}} / \mathrm{Su} 2=0.11 \sim 0.2$ and $\mathrm{t}_{1} / \mathrm{D}=0.25\left(\mathrm{Su} 1=2+2 \mathrm{z} \mathrm{kPa}, \mathrm{Su}_{2}=40 \mathrm{kPa}, \mathrm{Su} 3=30+1(\mathrm{z}-\right.$ $\left.\mathrm{t}_{1}-\mathrm{t}_{2}\right) \mathrm{kPa}$ ), the limiting squeezing depth (taken as the depth from where the spudcan started to sense the underlying stiff layer and consequently the resistance profile deviated from the one without the underlying layer) range is consistently about $\sim 0.18 \mathrm{D}$ from the surface of the stiff layer. A similar depth was reported by Hossain et al. (2011) from centrifuge model tests. 
446 A comparison of the penetration resistance profiles for $\mathrm{su2} / \mathrm{su}_{\mathrm{u}} \mathrm{s}=1.33$ and 2.5 (see Figures $44712 \mathrm{a} \sim 12 \mathrm{c}$ ) reflects that, in the middle layer, bearing response is higher and the curve is steeper 448 for higher $\mathrm{Su}_{2} / \mathrm{Su}_{3}$ s. This is yielded by the higher $\mathrm{Su2}$ and also associated with the soil 449 deformation extending deeper into the bottom layer of strength increasing with depth. 450 Potential for rapid leg run over a depth of 1.4D exists only when the effect of higher strength 451 ratio is supplemented by higher thickness ratio of $t_{2} / D=0.75$ (see Figure $12 \mathrm{c}$ ).

452 In most cases, soil backflow occurs in the bottom layer. The limiting cavity depth above the spudcan also increases as the strength ratio increases.

\section{Effect of thickness ratios ( $t_{1} / D$ and $\left.t_{2} / D\right)$}

455 The discussion in this section primarily focuses on the influence of $t_{2} / D$, as in most case 456 histories the $1^{\text {st }}$ layer of this type of soil deposit is thin and soft and it barely affects the 457 spudcan final penetration depth. The results are plotted in Figures 13a and 13b to explore the 458 effect of thickness ratio for $\mathrm{t}_{2} / \mathrm{D}=0.25,0.5$ and 0.75 , with an identical $\mathrm{t}_{1} / \mathrm{D}=0.25$ and $459 \mathrm{k} 1 \mathrm{D} / \mathrm{sum}=12$. The strength ratio at the interface between $2^{\text {nd }}$ and $3^{\text {rd }}$ layers are $\mathrm{Su} 2 / \mathrm{su} 3 \mathrm{~s}=1.33$ and 2.5 , with the bottom layer non-homogeneity factor $\mathrm{k} 3 \mathrm{D} / \mathrm{su3s}=0.4$.

Comparing Figures $13 \mathrm{a}$ and $13 \mathrm{~b}$, it can be seen that the effect of thickness ratio appears to be more pronounced for higher strength ratio $\mathrm{su2}_{2} / \mathrm{su3s}_{\mathrm{s}}$, i.e. for higher value of $\mathrm{su}_{2}$ as $\mathrm{su3s}_{\mathrm{s}}$ is constant. For a strength ratio of $\mathrm{su}_{2} / \mathrm{su}_{\mathrm{us}}=2.5\left(\mathrm{~s}_{\mathrm{u} 1}=2+2 \mathrm{z} \mathrm{kPa}, \mathrm{su}_{2}=75 \mathrm{kPa}, \mathrm{su}_{3}=30+1\left(\mathrm{z}-\mathrm{t}_{1}-\mathrm{t}_{2}\right) \mathrm{kPa}\right.$; see Figure 13b), a greater and steeper penetration resistance is mobilized in the thicker middle layer. The resistance profile remains somewhat constant through the stiff $\left(2^{\text {nd }}\right)$ layer and part

466 of the bottom layer. A rapid leg run of about 1.4D would occur for this deposit with a 467 sandwiched stiff layer of $t_{2} / D=0.75$. The effect of thickness ratio and the form of the penetration resistance profiles discussed above are consistent with observations from the centrifuge tests (see Figure 8 of Hossain et al. 2011). 
470 In the above analyses, the thickness of the top layer is $0.25 \mathrm{D}$. An analysis was also carried out 471 doubling the thickness $\mathrm{t}_{1}$ to $0.5 \mathrm{D}$ and the result is shown in Figure $13 \mathrm{c}\left(\mathrm{su}_{1}=2+2 \mathrm{z} \mathrm{kPa}, \mathrm{su}_{2}=\right.$ $\left.47240 \mathrm{kPa}, \mathrm{Su} 3=30+1\left(\mathrm{z}-\mathrm{t}_{1}-\mathrm{t}_{2}\right) \mathrm{kPa}\right)$. The limiting squeezing depth is consistent of about $473 \sim 0.18 \mathrm{D}$, although the squeezing effect is not so prominent for $\mathrm{t}_{1} / \mathrm{D}=0.5$ due to higher 474 strength ratio $\mathrm{Su}_{\mathrm{s}} / \mathrm{su}_{\mathrm{u} 2}=0.35$ (compared to 0.2 for $\mathrm{t}_{1} / \mathrm{D}=0.25$ ). The trend is similar, but the 475 profile lies below the curve for $t_{1} / D=0.25$ due to delayed influence of the middle stiff layer.

476 The depth of soil backflow is also affected by the thickness ratios $t_{1} / D$ and $t_{2} / D$. For $t_{1} / D=$ 4770.25 , squeezing dominates the behavior shortly $(\mathrm{d} / \mathrm{D}=\sim 0.07)$ after the spudcan's full 478 diameter penetrates into the ground and, consequently, soil starts to flow back at deep 479 penetration when the spudcan penetrates through the bottom layer. For $t_{1} / \mathrm{D}=0.5$, the 480 thickness of the very soft top layer is sufficient to allow soil backflow to occur before 481 squeezing and a downward soil deformation governing the behavior.

\section{Effect of non-homogeneity factor of bottom layer ( $\left.k_{3} \mathrm{D} / \mathrm{su3}_{\mathrm{s}}\right)$}

483 To explore this influence of strength non-homogeneity $\mathrm{k}_{3} \mathrm{D} / \mathrm{su}_{3}$ s comprehensively, analyses 484 have been undertaken for a clay with $\mathrm{su3s}_{\mathrm{s}} / \gamma^{\prime} \mathrm{D}=0.31$, but varying $\mathrm{k}_{3} \mathrm{D} / \mathrm{su3s}_{\mathrm{s}}$ between 0 and 1.2 485 for thickness ratios of $t_{1} / D=0.5$ and $t_{2} / D=0.75$ (Group VI, Table 1). For all cases, the top layer with $\mathrm{k}_{1} \mathrm{D} / \mathrm{sum}=7.2$ is underlain by the middle layer of uniform stiff clay with $\mathrm{Su2} / \mathrm{su3s}=$ layer strength gradient on punch-through potential.

Figure 14 shows the bearing resistance profiles. Severe punch-through with a negative postpeak response is evident in the bottom layer at $\mathrm{d} / \mathrm{D}=1.4 \sim 1.5$, following the initiation of soil

491 backflow. Except for the sediment with a uniform bottom layer (i.e. $\mathrm{k}_{3} \mathrm{D} / \mathrm{su}_{\mathrm{s} s}=0$ ), the 492 uncontrollable penetration continues until the rising capacity in the bottom layer comprising 
493

494

495

496

497

498

499

500

501

502

503

504

505

506

507

508

509

510

511

512

513

514

515

non-uniform clay, re-establishes the failure load at $\mathrm{d} / \mathrm{D}=1.7 \sim 2.2$. In the field, the spudcan would rapidly penetrate this distance.

The severity of punch-through reduces substantially as $\mathrm{k}_{3} \mathrm{D} / \mathrm{su3s}$ increases owing to the sharper increase in strength profile of the bottom layer. It is evident from Figure 14 that while severe punch-through happens for $\mathrm{k}_{3} \mathrm{D} / \mathrm{su}_{\mathrm{u}}=0$, moderate $(0.7 \mathrm{D})$ or mild $(0.3 \mathrm{D})$ punch-through may occur as $\mathrm{k}_{3} \mathrm{D} / \mathrm{su3s}$ approaches 1.2 . This is consistent with the effect reported by Hossain and Randolph (2010a, 2010b) on two-layer stiff-over-soft clays. They provided explanation for the effect of $\mathrm{k}_{2} \mathrm{D} / \mathrm{su2s}$ by the entirely different soil flow patterns for cases where all other parameters were identical but with different non-homogeneity factors $\left(\mathrm{k}_{2} \mathrm{D} / \mathrm{su2s}_{2}\right)$ of 0 and 0.6 .

Punch-through failure occurs in the bottom layer with the initiation of soil backflow. The depth of backflow increases as $\mathrm{k}_{3} \mathrm{D} / \mathrm{Su3s}$ reduces. From Figure $13 \mathrm{c}$, for similar thickness ratios of $t_{1} / D=0.5$ and $t_{2} / D=0.75$, backflow occurs in the top layer. The delayed backflow in Figure 14 is due to lower $\mathrm{k}_{1} \mathrm{D} / \mathrm{sum}$ of 7.2 (compared to 12 in Figure $13 \mathrm{c}$ ).

\section{Effect of accounting for strain rate and softening}

Similar to stiff-soft-stiff clay, analyses were also carried out for strain softened, rate dependent soil $\left(\delta_{\text {rem }}=0.3, \mu=0.1, \xi_{95}=12, \dot{\gamma}_{\text {ref }}=1.5 \% / \mathrm{h}\right)$. Two profiles are included in Figure $12 \mathrm{c}\left(\mathrm{su}_{1}=2+2 \mathrm{z} \mathrm{kPa}, \mathrm{su}_{2}=40\right.$ and $\left.75 \mathrm{kPa}, \mathrm{su}_{3}=30+1\left(\mathrm{z}-\mathrm{t}_{1}-\mathrm{t}_{2}\right) \mathrm{kPa}\right)$ for comparison. Accounting for strain softening and rate dependency has insignificant effect at shallow penetration depth in the $1^{\text {st }}$ soft layer. They exhibit with the potential for severe punchthrough while miniature punch-through or rapid leg run occurs for ideal soil. Additionally, soil backflow occurs earlier in the $1^{\text {st }}$ layer for spudcan penetration in strain softened, rate dependent soil. These are consistent with Figure 11. 


\section{Concluding Remarks}

517 Continuous penetration of spudcan foundations from the surface of three-layer seabed 518 sediments was investigated through 3D large deformation FE analyses using the CEL approach in Abaqus/Explicit. Two stratifications, including uniform stiff-soft-stiff and nonuniform clay with an interbedded stiff clay layer, commonly encountered in the field and identified as critical for potential punch-through failure, were considered. The effects of a practical range of normalized soil properties and layer geometries on the bearing response and soil flow mechanisms were discussed in the context of punch-through and rapid leg run (for stiff-over-soft) and squeezing (for the reverse). The following key conclusions can be drawn from the results presented in the paper.

1. For uniform stiff-soft-stiff clays, the presence of the bottom stiff clay layer within a short distance of $\left(t_{1}+t_{2}\right)=1 D$ allowed for sensing that layer from the beginning of spudcan penetration in the top layer. This inhibited the potential for punch-through (apart from rapid leg run for $\mathrm{t}_{1} / \mathrm{D}=0.75$ and $\mathrm{suls}_{\mathrm{s}} / \mathrm{Su}_{2}=3$ ), which would occur for a higher thickness ratio of $\left(t_{1}+t_{2}\right) / D=1.5$ and for some identical, but two-layer stiffover-soft clay deposits.

2. The soil plug trapped at the base of the advancing spudcan allowed for early sensing of the bottom stiff layer and hence enhanced the corresponding limiting squeezing depth.

3. The resistance profile from a spudcan continuous penetration on a three-layer stiff-softstiff clay deposit was significantly different from the combined profiles resulted from two separate analyses on $1^{\text {st }}-2^{\text {nd }}$ layer and $2^{\text {nd }}-3^{\text {rd }}$ layer even after an appropriate depth factor was accounted for. As such for using the ISO suggested bottom-up design approach, combining the punch-through (for stiff-over-soft layering) and squeezing (for 

the reverse) criteria for two layer systems, at least appropriate plug heights and limiting squeezing depths are required to be considered.

4. For non-uniform clay with an interbedded stiff layer, spudcan bearing response in the top layer was dominated by squeezing, with a consistent limiting squeezing depth of about $\sim 0.18 \mathrm{D}$.

5. In contrast to ISO recommendation, the soft soils in between the advancing spudcan base and the stronger layer did not squeeze out completely instead some of the trapped material was forced into the stronger underlying layer.

6. The potential for punch-through failure or rapid leg run was shown to exist for $t_{2} / \mathrm{D} \geq$ 0.5 and $\mathrm{su3s} / \mathrm{Su2}=0.4$.

7. The non-uniform bottom layer with a positive strength gradient was shown to have a favorable influence on reducing punch-though distance. As $\mathrm{k}_{3} \mathrm{D} / \mathrm{s}_{\mathrm{u} 3 \mathrm{~s}}$ increased from 0.4 to 1.2 , the punch-though distance of $0.75 \mathrm{D}$ decreased to $0.3 \mathrm{D}$.

8. At very shallow penetration depths, the combined effect of strain softening and rate dependency had insignificant influence on spudcan penetration resistance. With the progress of penetration, the profiles for strain softened, rate dependent soils were diverged gradually from and became lower than that for ideal soil, leading to enhanced likelihood and severity for punch-through.

\section{Acknowledgements}

The first author is the recipient of the University of Western Australia SIRF and UIS scholarships. The $2^{\text {nd }}$ author is an Australian Research Council (ARC) Discovery Early Career Researcher Award (DECRA) Fellow and is supported by the ARC Project DE140100903. 
562 The research presented here was undertaken with support from the ARC and the industry

563 partner Keppel Offshore and Marine Pte Ltd, Singapore through the ARC Linkage Project

564 LP110100174. This work forms part of the activities of the Centre for Offshore Foundation

565 Systems (COFS), currently supported as a node of the Australian Research Council Centre of

566 Excellence for Geotechnical Science and Engineering and as a Centre of Excellence by the

567 Lloyd's Register Foundation. This support is gratefully acknowledged. 


\section{NOMENCLATURE}

569 A spudcan plan area at largest section

570 D foundation diameter at largest section

$571 \mathrm{~d}$ penetration depth of spudcan base (lowest point at largest section) measured from $572 \quad$ mudline

573 E Young's modulus

$574 \mathrm{H} \quad$ open cavity depth after spudcan installation (taken as identical to backflow depth)

$575 h_{\min } \quad$ minimum element size in numerical model

$576 \quad \mathrm{k} 1 \quad$ rate of increase of shear strength within $1^{\text {st }}$ layer

$577 \quad \mathrm{k} 2 \quad$ rate of increase of shear strength within $2^{\text {nd }}$ layer

$578 \quad \mathrm{k}_{3} \quad$ rate of increase of shear strength within $3^{\text {rd }}$ layer

579 P penetration resistance of spudcan foundation

$580 \quad$ qnet net bearing pressure

581 qnet0 net bearing pressure in weightless soil

$582 \quad \mathrm{Su} \quad$ undrained shear strength of soil

$583 \quad$ Sul undrained shear strength of $1^{\text {st }}$ layer soil

584 Suls undrained shear strength of $1^{\text {st }}$ layer soil at $1^{\text {st }}-2^{\text {nd }}$ layer interface

585 Su2 undrained shear strength of $2^{\text {nd }}$ layer soil

586 Su2s undrained shear strength of $2^{\text {nd }}$ layer soil at $1^{\text {st }}-2^{\text {nd }}$ layer interface 
$587 \quad$ Su3 undrained shear strength of $3^{\text {rd }}$ layer soil

588 Su3s undrained shear strength of $3^{\text {rd }}$ layer soil at $2^{\text {nd }}-3^{\text {rd }}$ layer interface

589 Sum undrained shear strength at mudline

$590 \quad \mathrm{t}_{1} \quad$ thickness of $1^{\text {st }}$ layer soil

$591 \quad \mathrm{t}_{2} \quad$ thickness of $2^{\text {nd }}$ layer soil

$592 \mathrm{~V} \quad$ volume of embedded spudcan foundation including shaft

$593 \quad$ Vsp spudcan penetration velocity in numerical simulation

$594 \quad$ z $\quad$ depth below soil surface

$595 \quad \gamma^{\prime} \quad$ effective unit weight of soil

596 


\section{References}

Aust, T. (1997). Accident to the mobile offshore drilling unit Maersk Victory on 16 November 1996, Mines and Energy Resources, South Australia.

Bennett and Associates, L. L. C, and Offshore Technology Development INC. (2005). "Jack up units: a technical primer for the offshore industry professional." < http://www.bennettoffshore.com/primer.html >.

Brennan, R., Diana, H., Stonor, R. W. P., Hoyle, M. J .R., Cheng, C. P., Martin, D., and Roper, R. (2006). "Installing jackups in punch-through-sensitive clays." Proc., Offshore Technology Conf., Houston, OTC 18268.

Brown, J. D., and Meyerhof, G. G. (1969). "Experimental study of bearing capacity in layered clays." Proc., $7^{\text {th }}$ Int. Conf. on Soil Mech. and Found. Eng., Mexico 2, 45-51.

Carter, J. P., and Balaam, N. P. (1990). AFENA user's manual, Centre for Geotechnical Research, The University of Sydney, Sydney, Australia.

Castleberry II, J. P., and Prebaharan, N. (1985). "Clay crusts of the Sunda Shelf - a hazard to jack-up operations." Proc., $8^{\text {th }}$ Southeast Asian Geotech. Conf., Kuala Lumpur, 40-48.

Chan, N. H. C., Paisley, J. M., and Holloway, G. L. (2008). "Characterization of soils affected by rig emplacement and Swiss cheese operations - Natuna Sea, Indonesia, a case study." Proc., $2^{\text {nd }}$ Jack-up Asia Conf. and Exhibition, Singapore.

Club des Actions de Recherche sur les Ouvrages en Mer (CLAROM). (1993). Design guides for offshore structures, P. Le Tirant and C. Pérol, eds., Paris.

Edwards, D. H., and Potts, D. M. (2004). "The bearing capacity of circular footing under "punch-through" failure." Proc., $9^{\text {th }}$ Int. Symp. on Numerical Models in Geomechanics, Ottawa, 493-498.

Einav, I., and Randolph, M. F. (2005). “Combining upper bound and strain path methods for evaluating penetration resistance.” Int. J. Numer. Methods in Eng., 63(14), 1991-2016.

Erbrich, C. T. (2005). “Australian frontiers - Spudcans on the edge.” Proc., $1^{\text {st }}$ Int. Symp. on Frontiers in Offshore Geotechnics (ISFOG), Taylor \& Francis, London, 49-74. 
624

625

626

627

628

629

630

631

632

633

634

635

636

637

638

639

640

641

642

643

644

645

646

647

648

649

650

Handidjaja, P., Somehsa, P., and Manoj, M. (2004). “'Swiss-cheese' - A method of degrading soil crust and minimizing risk to punch through problem on the installation of mobile offshore drilling unit (MODU)." Proc., 15 th Southeast Asian Geotechnical Society Conf., Bangkok, 303-306.

Hossain, M. S., and Randolph, M. F. (2010a). "Deep-penetrating spudcan foundations on layered clays: centrifuge tests." Géotechnique, 60(3), 157-170.

Hossain, M. S., and Randolph, M. F. (2010b). "Deep-penetrating spudcan foundations on layered clays: numerical analysis." Géotechnique, 60(3), 171-184.

Hossain, M. S., and Randolph, M. F. (2009a). "Effect of strain rate and strain softening on the penetration resistance of spudcan foundations on clay." Int. J. Geomech., 10.1061/(ASCE)1532-3641(2009)9:3(122),122-132.

Hossain, M. S., and Randolph, M. F. (2009b). "New mechanism-based design approach for spudcan foundations on single layer clay." J. Geotech. Geoenviron. Eng., 10.1061/(ASCE)GT.1943-5606.0000054, 1264-1274.

Hossain, M. S., and Randolph, M. F. (2009c). "New mechanism-based design approach for spudcan foundations on stiff-over-soft clay." Proc., Offshore Technology Conf., Houston, OTC 19545.

Hossain, M. S., Randolph, M. F., and Saunier, Y. N. (2011). "Spudcan deep penetration in multi-layered fine-grained soils.” Int. J. Phys. Modelling in Geotech., 11(3), 100-115.

Hu, Y., and Randolph, M. F. (1998). “A practical numerical approach for large deformation problems in soil." Int. J. Numer. Anal. Methods Geomech., 22(5), 327-350.

InSafeJIP (2010). Improved guidelines for the prediction of geotechnical performance of spudcan foundations during installation and removal of jack-up units, RPS Energy, Abingdon, Oxfordshire, U.K.

International Organization for Standardization (ISO). (2011). "Petroleum and Natural Gas Industries - Site Specific Assessment of Mobile Offshore Units - Part 1: Jack-ups.” ISO 19905-1, Geneva. 
Jack, R. L., Hoyle, M. J. R., Hunt, R. J., and Smith, N. P. (2007). “Jack-up accident statistics: Lots to learn!" Proc., $11^{\text {th }}$ Int. Conf. the Jack-up Plat Form Design, Construction and Operation, London.

Jack, R. L., Hoyle, M. J. R., Smith, N. P., and Hunt, R. J. (2013). “Jack-up accident statistics - A further update." Proc., $11^{\text {th }}$ Int. Conf. the Jack-up Plat Form Design, Construction and Operation, London.

Kostelnik, A., Guerra, M., Alford, J., Vazquez, J., and Zhong, J. (2007). “Jackup mobilization in hazardous soils." SPE Drilling and Completion, 22(1), 4-15.

Lu, Q., Randolph, M. F., Hu, Y., and Bugarski, I. C. (2004). “A numerical study of cone penetration in clay." Géotechnique, 54(4), 257-267.

Lunne, T., Berre, T., Andersen, K. H., Strandvik, S., and Sjursen, M. (2006). "Effects of sample disturbance and consolidation procedures on measured shear strength of soft marine Norwegian clays.” Can. Geotech. J., 43(7), 726-750.

Martin, C. M., and Randolph, M. F. (2001). "Application of the lower and upper bound theorems of plasticity to collapse of circular foundations." Proc., $10^{\text {th }}$ Int. Conf. on Computer Methods and Advance Geomechanics, Vol. 2, Tucson, Ariz., 1417-1428.

Maung, U. M., and Ahmad, C. K. M. (2000). "Swiss cheesing to bring in a jack-up rig at Anding location.” Proc., IADC/SPE Asia Pacific Drilling Technology, Kuala Lumpur, IADC/SPE 62755.

Menzies, D., and Lopez, C. R. (2011). "Four atypical jack-up rig foundation case histories." Proc., 13 $3^{\text {th }}$ Int. Conf. on the Jack-up Platform: Design, Construction and Operation, London.

Menzies, D., and Roper, R. (2008). "Comparison of jackup rig spudcan penetration methods in clay." Proc., Offshore Technology Conf., Houston, OTC 19545.

Merifield, R. S., and Nguyen, V. Q. (2006). "Two- and three-dimensional bearing capacity solutions for footing on two-layered clays.” Geomech. Geoengng, 1(2), 151-162.

Meyerhof, G. G., and Chaplin, T. K. (1953). "The compression and bearing capacity of cohesive layers.” Br. J. Appl. Phys., 4(1), 20-26. 
679

680

681

682

683

684

685

686

687

688

689

690

691

692

693

694

695

696

697

698

699

700

701

702

703

704

705

706

707

Qiu, G., and Grabe, J. (2011). "Explicit modelling of cone and strip footing penetration under drained and undrained conditions using a visco-hypoplastic model." geotechnik, 34(3), 205-217.

Qiu, G., and Grabe, J. (2012). "Numerical investigation of bearing capacity due to spudcan penetration in sand overlying clay." Can. Geotech. J., 49(12), 1393-1407.

Qiu, G., and Henke, S. (2011). "Controlled installation of spudcan foundations on loose sand overlying weak clay." Mar. Struct., 24(4), 528-550.

Randolph, M. F. (2004). "Characterisation of soft sediments for offshore applications.” Proc., $2^{\text {nd }}$ Int. Conf. on Site Characterization, Porto, Portugal, Vol. 1, Millpress Science Publisher, Rotterdam, 209-231 (Keynote Lecture).

Randolph, M. F., Cassidy, M. J., Gourvenec, S., and Erbrich, C. J. (2005). "Challenges of offshore geotechnical engineering. State of the Art paper." Proc., Int. Conf. on Soil Mech. and Found. Eng., Int. Society for Soil Mechanics and Geotechnical Engineering, London, 123-176.

Tho, K. K., Leung, C. F., Chow, Y. K., and Swaddiwudhipong, S. (2012). "Eulerian finiteelement technique for analysis of jack-up spudcan penetration.” Int. J. Geomech., 12(1), 64-73.

Thorne, C. P., Wang, C. X., and Carter, J. P. (2004). "Uplift capacity of rapidly loaded strip anchors in uniform strength clay." Géotechnique, 54(8), 507-517.

Wang, C. X., and Carter, J. P. (2002). "Deep penetration of strip and circular footings into layered clays.” Int. J. Geomech., 2(2), 205-232.

Wong, P. C., Templeton III, J. S., Purwana, O. A., Hofstede, H., Cassidy, M. J., Hossain, M. S., and Martin, C. M. (2012). "Foundation modeling and assessment in the new ISO standard 19905-1." Proc., Offshore Technology Conf., Houston, OTC 23521.

Young, A. G., Remmes, B. D., and Meyer, B. J. (1984). "Foundation Performance of offshore jack-up drilling rigs.” J. Geotech. Engrg., 10.1061/(ASCE)07339410(1984)110:7(841), 841-859.

Zheng, J., Hossain, M. S., and Wang, D. (2013). "3D large deformation FE analysis of spudcan and cone penetration on three-layer clays." Proc., $23^{\text {rd }}$ Int. Offshore and 
Polar Engineering Conf., Int. Society of Offshore and Polar Engineers, Cupertino, CA, 453-460.mark

710 Zhou, M., Hossain, M. S., Hu, Y., and Liu, H. (2012). "Behaviour of ball penetrometer in uniform single- and double-layer clays." Géotechnique, 63(8), 682-694.

712 Zhou, H., and Randolph, M. F. (2007). "Computational techniques and shear band development for cylindrical and spherical penetrometers in strain-softening clay." Int. J. Geomech., 10.1061/(ASCE)1532-3641(2007)7:4(287), 287-295.

715 Zhou, H., and Randolph, M. F. (2009). "Resistance of full-flow penetrometers in ratedependent and strain-softening clay." Géotechnique, 59(2), 79-86. 
Table 1. Summary of LDFE analyses performed

\begin{tabular}{|c|c|c|c|c|c|c|c|c|c|}
\hline Analysis & $\mathbf{S}_{\mathbf{u} 1 \mathbf{s}} / \mathbf{S}_{\mathbf{u} 2}$ & $\mathbf{t}_{1} / \mathbf{D}$ & $\begin{array}{l}\mathbf{k}_{1} \mathbf{D} / \\
\mathbf{S}_{\mathbf{u m}}\end{array}$ & $\mathbf{S}_{\mathbf{u} 2} / \mathbf{S}_{\mathbf{u} 3 \mathbf{s}}$ & $\mathbf{t}_{2} / \mathbf{D}$ & $\begin{array}{l}\mathbf{S}_{\mathbf{u} 3 \mathbf{s}} / \\
\gamma^{\prime} \mathbf{D}\end{array}$ & $\mathbf{k}_{3} \mathbf{D} / \mathbf{s u}_{\mathbf{u} 3}$ & $\begin{array}{c}\text { Spudcan } \\
\text { base }\end{array}$ & Remarks \\
\hline Group I & $\begin{array}{c}1,2 \text { and } \\
10\end{array}$ & 1.0 & 0 & - & Infinite & - & - & Smooth & $\begin{array}{l}\text { Comparison } \\
\text { with LDFE } \\
\text { results of Wang } \\
\text { and Carter } \\
(2002)\end{array}$ \\
\hline Group II & $\begin{array}{l}1.25, \\
1.67,2.5 \\
\text { and } 5\end{array}$ & 0.5 & 0 & - & Infinite & - & - & Rough & $\begin{array}{l}\text { Comparison } \\
\text { with LDFE } \\
\text { results of } \\
\text { Hossain and } \\
\text { Randolph } \\
(2010 \mathrm{~b})\end{array}$ \\
\hline \multirow{2}{*}{ Group III } & 0.2 & 0.38 & 3.6 & 2.6 & 0.58 & 0.1 & 0.81 & \multirow{2}{*}{ Rough } & $\begin{array}{l}\text { Comparison } \\
\text { with centrifuge } \\
\text { test T6 (Hossain } \\
\text { et al. } 2011 \text { ) }\end{array}$ \\
\hline & 1.82 & 0.42 & 0.6 & 0.33 & 0.5 & 0.38 & 0 & & $\begin{array}{l}\text { Comparison } \\
\text { with centrifuge } \\
\text { test T8 (Hossain } \\
\text { et al. } 2011 \text { ) }\end{array}$ \\
\hline $\begin{array}{l}\text { Group } \\
\text { IV }\end{array}$ & $\begin{array}{c}1.25,2 \\
\text { and } 3\end{array}$ & $\begin{array}{c}0.25, \\
0.5 \text { and } \\
0.75\end{array}$ & 0 & 0.53 & $\begin{array}{c}0.25, \\
0.5 \text { and } \\
0.75\end{array}$ & $\begin{array}{l}0.16 \\
\text { and } \\
0.78\end{array}$ & 0 & Rough & $\begin{array}{l}\text { Parametric } \\
\text { study for } \\
\text { uniform stiff- } \\
\text { soft-stiff clay } \\
\text { profile }\end{array}$ \\
\hline Group V & $\begin{array}{l}0.11,0.2 \\
\text { and } 0.35\end{array}$ & $\begin{array}{c}0.25 \\
\text { and } 0.5\end{array}$ & 12 & $\begin{array}{c}1.33 \\
\text { and } 2.5\end{array}$ & $\begin{array}{c}0.25 \\
0.5 \text { and } \\
0.75\end{array}$ & 0.31 & 0.4 & Rough & $\begin{array}{l}\text { Parametric } \\
\text { study for non- } \\
\text { uniform clay } \\
\text { with an } \\
\text { interbedded stiff } \\
\text { clay profile }\end{array}$ \\
\hline $\begin{array}{c}\text { Group } \\
\text { VI }\end{array}$ & 0.31 & 0.5 & 7.2 & 2.5 & 0.75 & 0.31 & $\begin{array}{l}0,0.4 \\
0.8 \text { and } \\
1.2\end{array}$ & Rough & $\begin{array}{l}\text { Exploration of } \\
\text { the effect of } \\
\text { bottom layer } \\
\text { strength non- } \\
\text { homogeneity }\end{array}$ \\
\hline
\end{tabular}




\section{No. of Figure: 14}

Fig. 1 Typical seabed strength profiles with potential for punch-through: (a) Uniform stiff-soft-stiff clay; (b) Non-uniform clay with an interbedded stiff layer

Fig. 2 Schematic diagram of embedded spudcan foundation showing idealized open cavity

Fig. 3 Typical mesh used in CEL analyses

Fig. 4 Comparison between results of LDFE analysis using CEL and RITSS: (a) Circular footing on weightless uniform stiff-over-soft clay (Group I, Table 1); (b) Spudcan on weighty uniform stiff-over-soft clay (Group II, Table 1)

Fig. 5 Comparison between results of LDFE analysis and centrifuge test data (Group III, Table 1): (a) Test T6 $\left(s_{\mathrm{u} 1}=s_{\mathrm{u} 3}=2+0.6 \mathrm{z} \mathrm{kPa}, \mathrm{s}_{\mathrm{u} 2}=23 \mathrm{kPa}\right)$; (b) Test T8 $\left(\mathrm{s}_{\mathrm{u} 1}=\right.$ $\left.16+0.8 \mathrm{z} \mathrm{kPa}, \mathrm{s}_{\mathrm{u} 2}=11 \mathrm{kPa}, \mathrm{s}_{\mathrm{u} 3}=33 \mathrm{kPa}\right)$

Fig. 6 Soil failure mechanisms during spudcan penetration: (a) early squeezing due to trapped soil plug $\left(\mathrm{d} / \mathrm{D}=0.48, \mathrm{~s}_{\mathrm{u} 1}=120 \mathrm{kPa}, \mathrm{s}_{\mathrm{u} 2}=40 \mathrm{kPa}, \mathrm{su}_{3}=75 \mathrm{kPa}, \mathrm{t}_{1} / \mathrm{D}=\mathrm{t}_{2} / \mathrm{D}\right.$ $=0.5)$; (b) Layered soil plug comprising soft soil from top layer $\left(\mathrm{d} / \mathrm{D}=\mathbf{0 . 5 5}, \mathrm{s}_{\mathrm{u} 1}=\right.$ $\left.2+2 \mathrm{z} \mathrm{kPa}, \mathrm{su}_{2}=75 \mathrm{kPa}, \mathrm{su}_{3}=30+1\left(\mathrm{z}-\mathrm{t}_{1}-\mathrm{t}_{2}\right) \mathrm{kPa}, \mathrm{t}_{1} / \mathrm{D}=\mathrm{t}_{2} / \mathrm{D}=\mathbf{0 . 2 5}\right)$

Fig. 7 Effect of strength ratio $\left(\mathrm{s}_{\mathrm{u} 1 \mathrm{~s}} / \mathrm{s}_{\mathrm{u} 2}\right)$ on bearing behavior: uniform stiff-soft-stiff clay $\left(s_{u 3 s} / \gamma^{\prime} D=0.78\right.$, rough; Group IV, Table 1): (a) $t_{1} / D=0.75, t_{2} / D=0.25 ;(b) t_{1} / D=$ $0.5, t_{2} / D=0.5 ;(c) t_{1} / D=0.25, t_{2} / D=0.75$

Fig. 8 Effect of thickness ratios $\left(t_{1} / D\right.$ and $\left.t_{2} / D\right)$ on bearing behavior for $\left(t_{1}+t_{2}\right) / D=1.0$ : uniform stiff-soft-stiff clay ( $s_{u 3 s} / \gamma^{\prime} D=0.78$, rough; Group IV, Table 1): (a) $\mathbf{S}_{\mathrm{u} 1 \mathrm{~s}} / \mathrm{su}_{\mathrm{u} 2}$ $=3 ;(b) S_{u 1 s} / S_{u 2}=2 ;(c) S_{u 1 s} / S_{u 2}=1.25$ 
Fig. 9 Effect of thicker top and middle layers on bearing behaviour: uniform stiff-softstiff clay $\left(s_{u 1 s} / s_{u 2}=3, s_{u 3 s} / \gamma^{\prime} D=0.78\right.$, rough; Group IV, Table 1)

Fig. 10 Effect of normalized strength $\left(s_{u 3 s} / \gamma^{\prime} D\right)$ on bearing behavior: uniform stiff-softstiff clay $\left(s_{u 1 s} / s_{u 2}=3, s_{u 2} / s_{u 3 s}=0.53, t_{1} / D=t_{2} / D=0.75\right.$, rough; Group IV, Table 1)

Fig. 11 Comparison of results with and without the effects of strain softening and rate dependency ( $s_{u 3 s} / \gamma^{\prime} D=0.78$, rough; Group IV, Table 1)

Fig. 12 Effect of strength ratio $\left(\mathrm{s}_{\mathrm{u} 2} / \mathrm{s}_{\mathrm{u} 3 \mathrm{~s}}\right)$ on bearing behavior: non-uniform clay with an interbedded stiff layer $\left(\mathrm{s}_{\mathrm{u} 3 \mathrm{~s}} / \gamma^{\prime} \mathrm{D}=\mathbf{0 . 3 1}, \mathrm{k}_{1} \mathrm{D} / \mathrm{s}_{\mathrm{um}}=12, \mathrm{k}_{3} \mathrm{D} / \mathrm{s}_{\mathrm{u} 3 \mathrm{~s}}=0.4\right.$, rough; Group V, Table 1): (a) $t_{1} / D=0.25, t_{2} / D=0.25 ;$ (b) $t_{1} / D=0.25, t_{2} / D=0.5 ;$ (c) $t_{1} / D=0.25$, $\mathbf{t}_{2} / \mathrm{D}=\mathbf{0 . 7 5}$

Fig. 13 Effect of thickness ratios $\left(t_{1} / D\right.$ and $\left.t_{2} / D\right)$ on bearing behavior: non-uniform clay with an interbedded stiff layer $\left(s_{u 3 s} / \gamma^{\prime} D=0.31, k_{1} D / s_{u m}=12, k_{3} D / s_{u 3 s}=0.4\right.$, rough; Group V, Table 1): (a) $s_{\mathrm{u} 2} / \mathrm{s}_{\mathrm{u} 3 \mathrm{~s}}=1.33, \mathrm{t}_{1} / \mathrm{D}=\mathbf{0 . 2 5}$; (b) $\mathrm{s}_{\mathrm{u} 2} / \mathrm{s}_{\mathrm{u} 3 \mathrm{~s}}=2.5, \mathrm{t}_{1} / \mathrm{D}=\mathbf{0 . 2 5}$; (c) $\mathrm{Su}_{\mathrm{u} 2} / \mathrm{Su}_{\mathrm{us}}=\mathbf{1 . 3 3}, \mathrm{t}_{\mathbf{2}} / \mathrm{D}=\mathbf{0 . 7 5}$

Fig. 14 Effect of bottom layer non-homogeneity $\left(k_{3} D / s_{u 3 s}\right)$ on bearing behavior: nonuniform clay with an interbedded stiff layer $\left(s_{u 3 s} / \gamma^{\prime} D=0.31, t_{1} / D=0.5, t_{2} / D=0.75\right.$, $\mathrm{k}_{1} \mathrm{D} / \mathrm{s}_{\mathrm{um}}=7.2$, rough; Group VI, Table 1) 


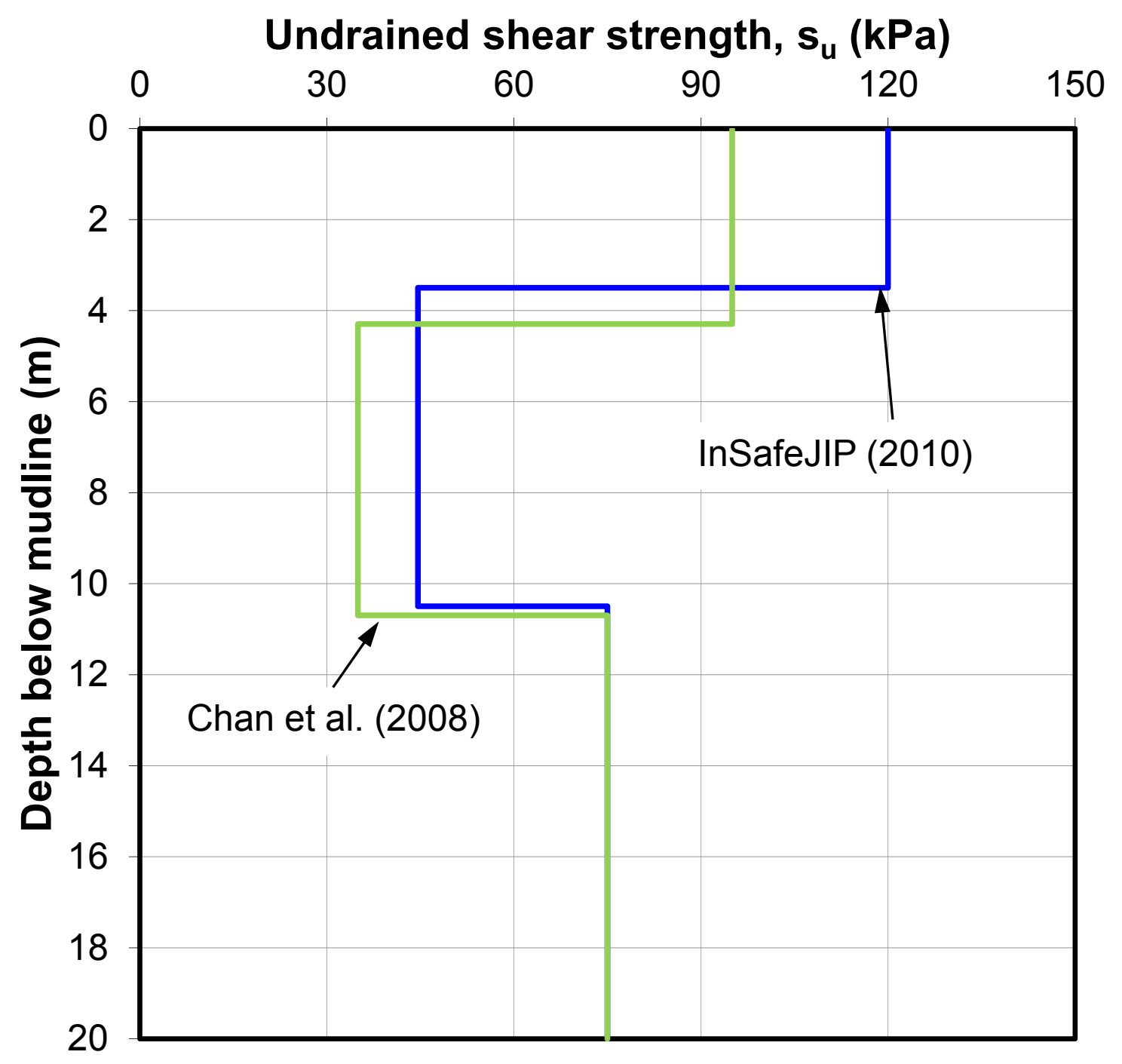




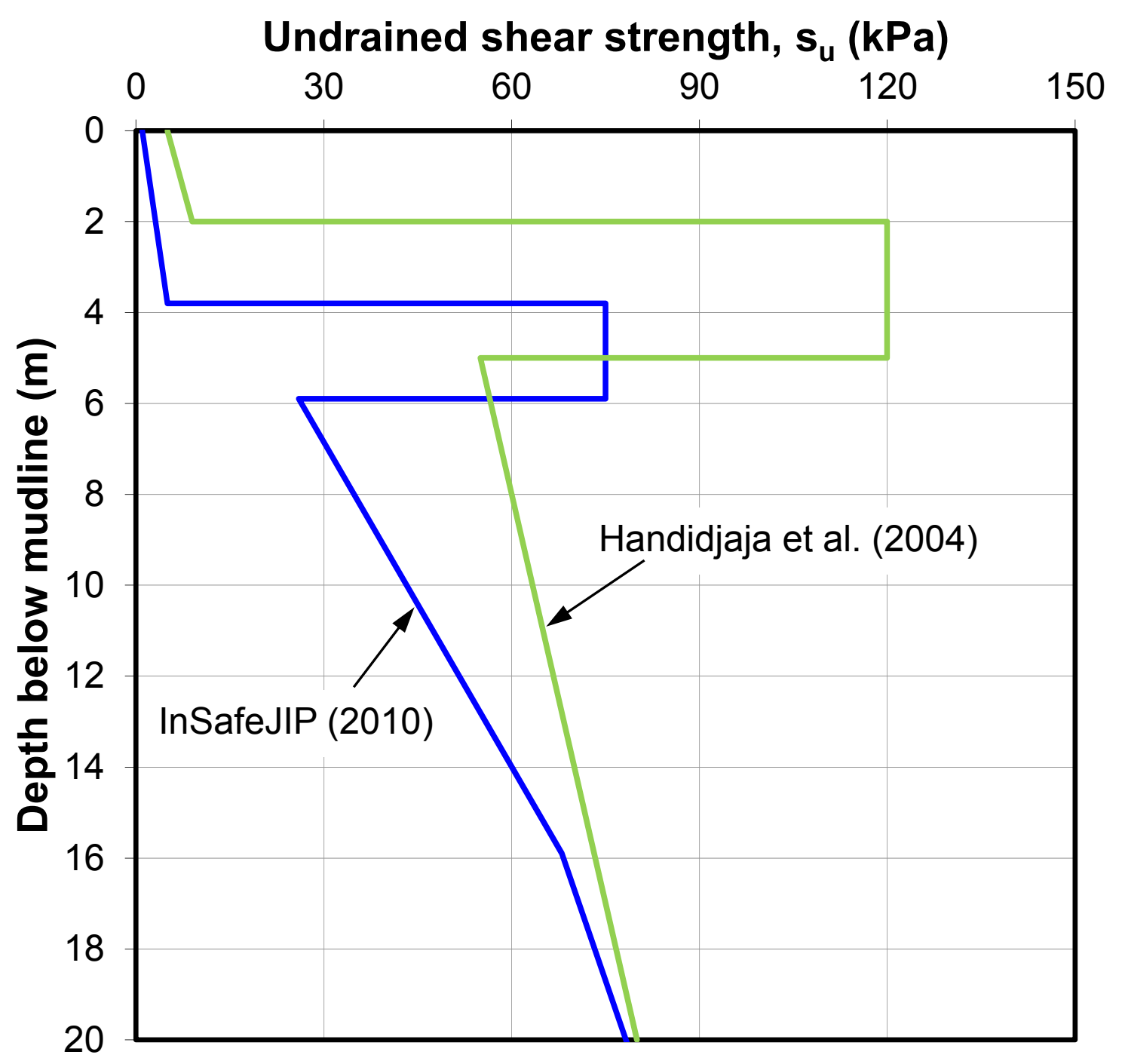




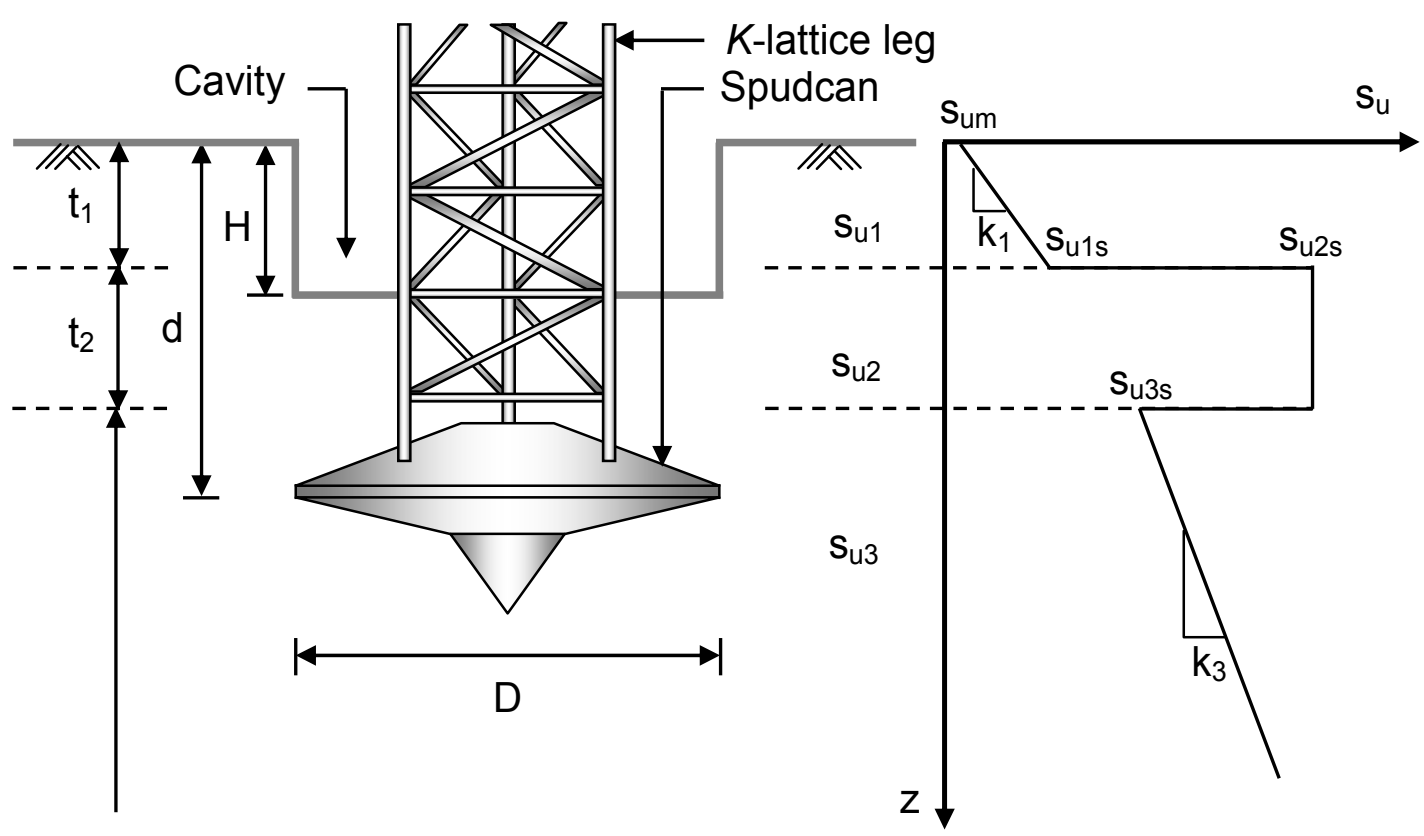




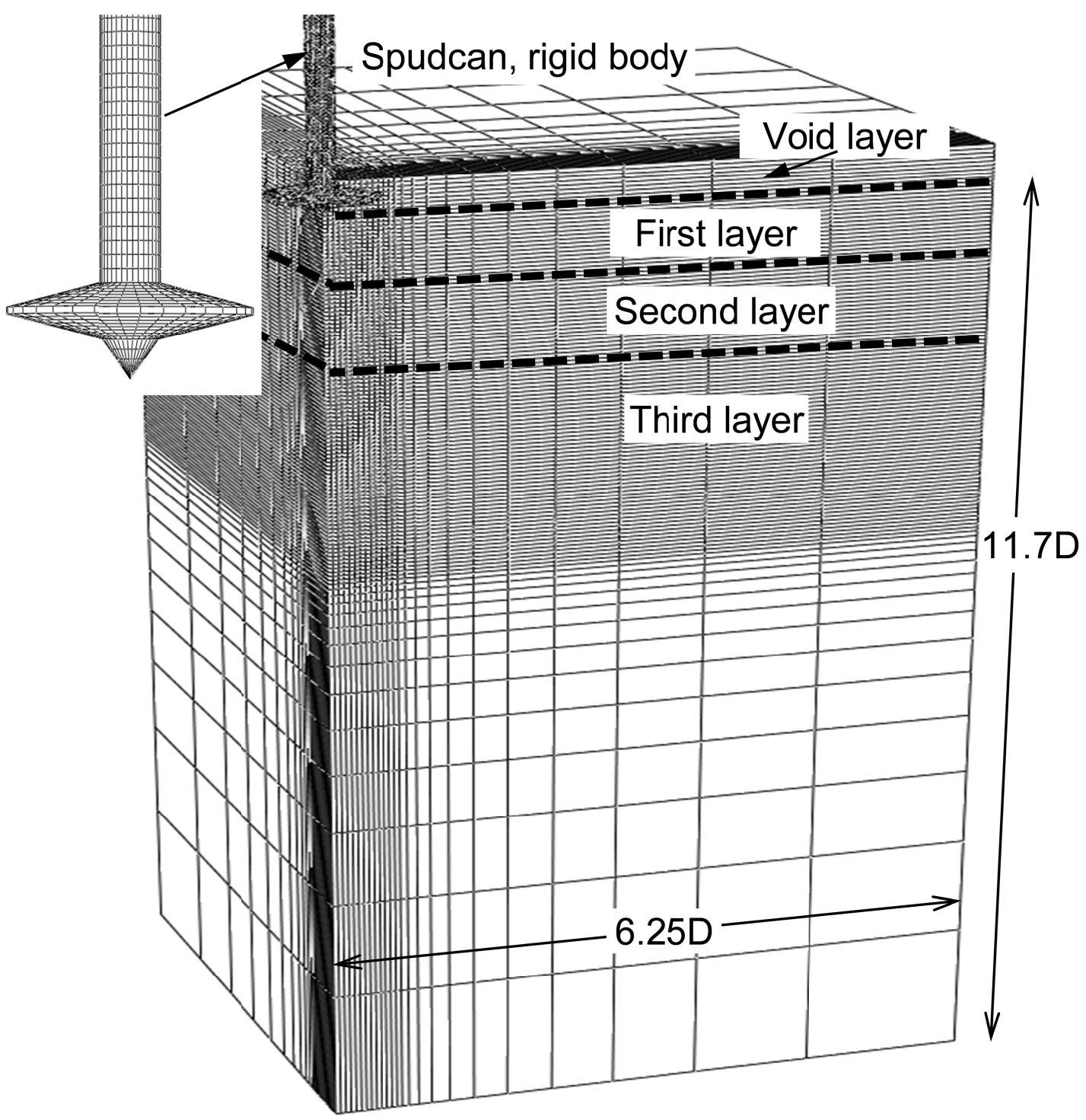




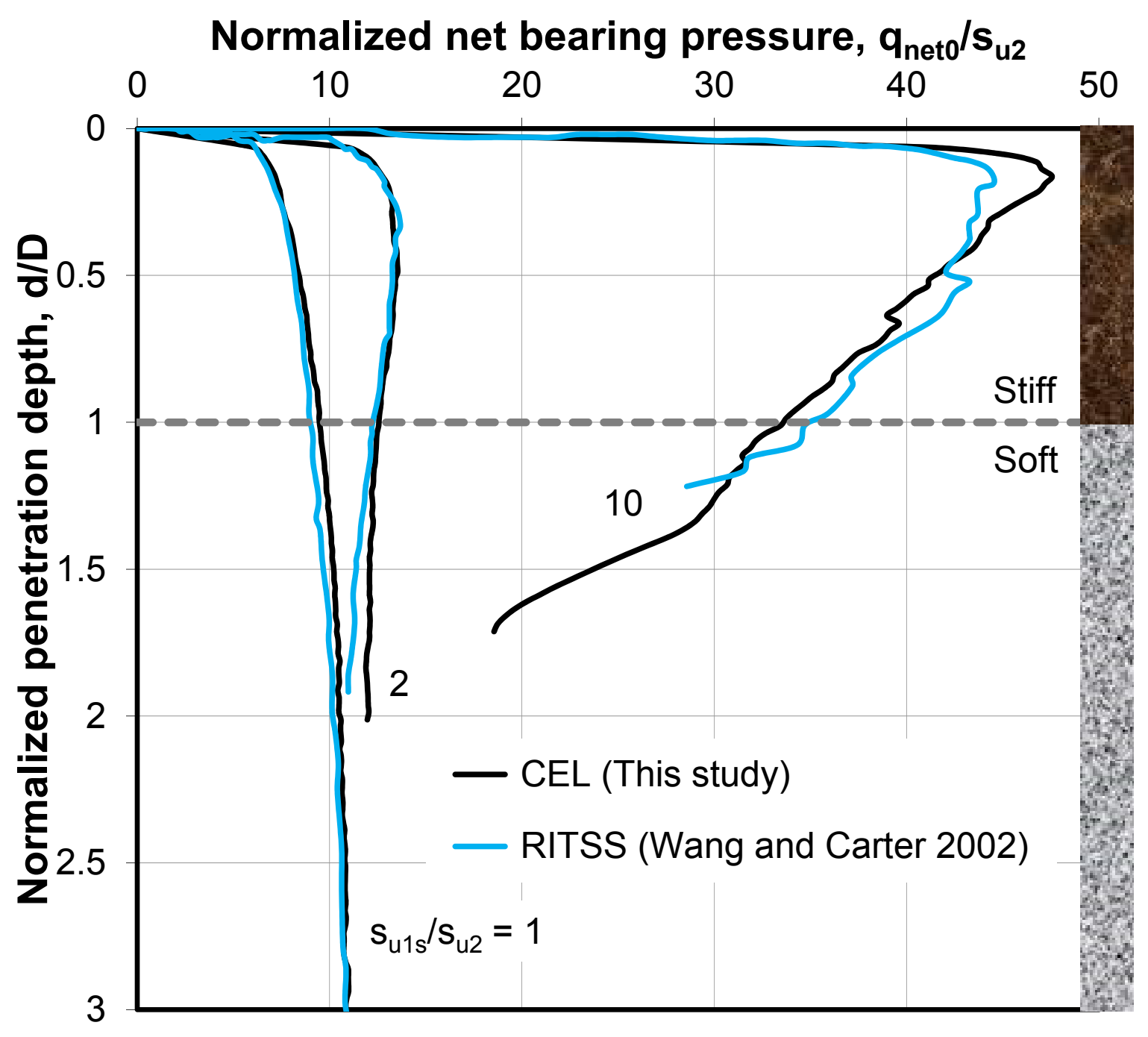




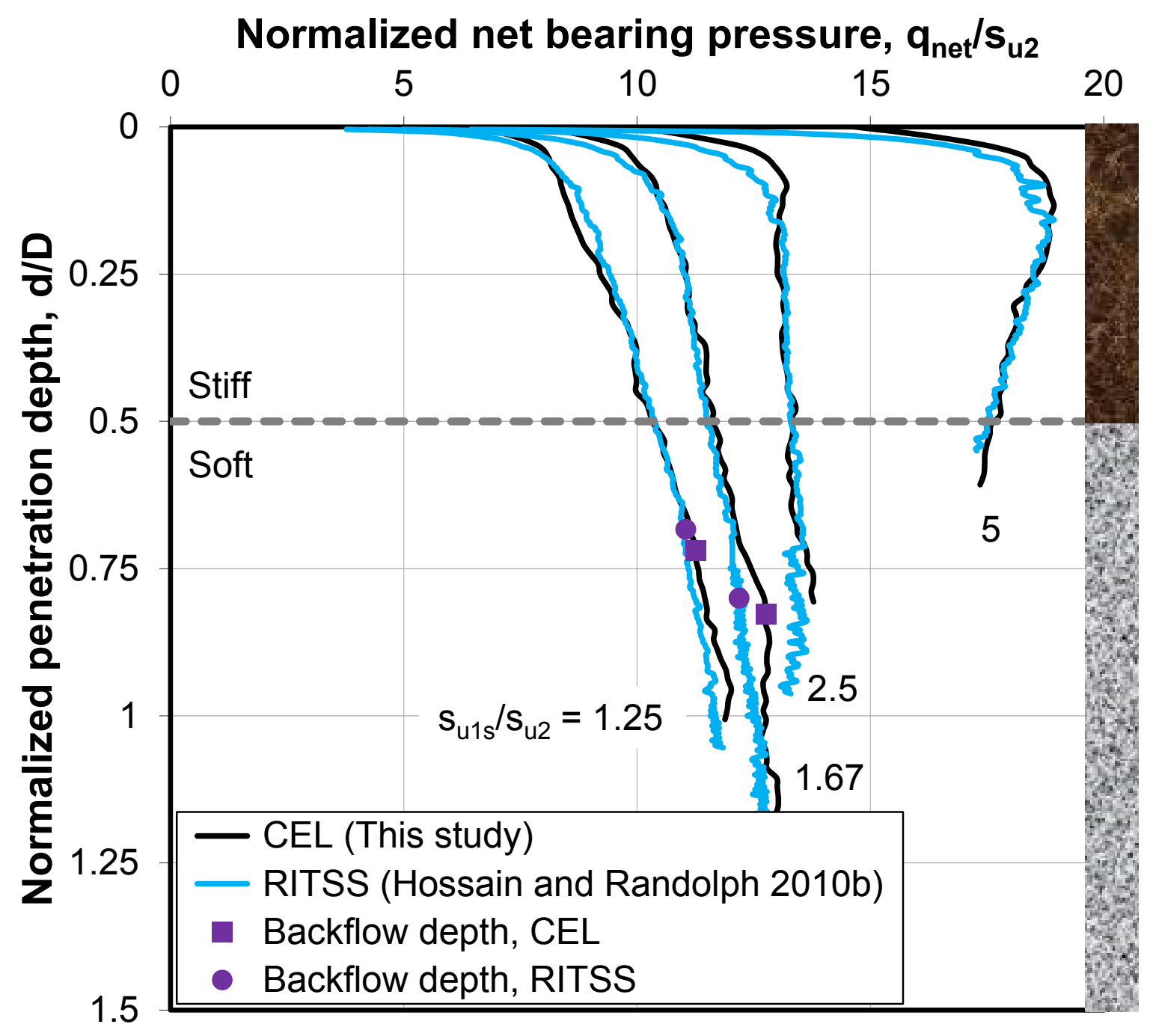




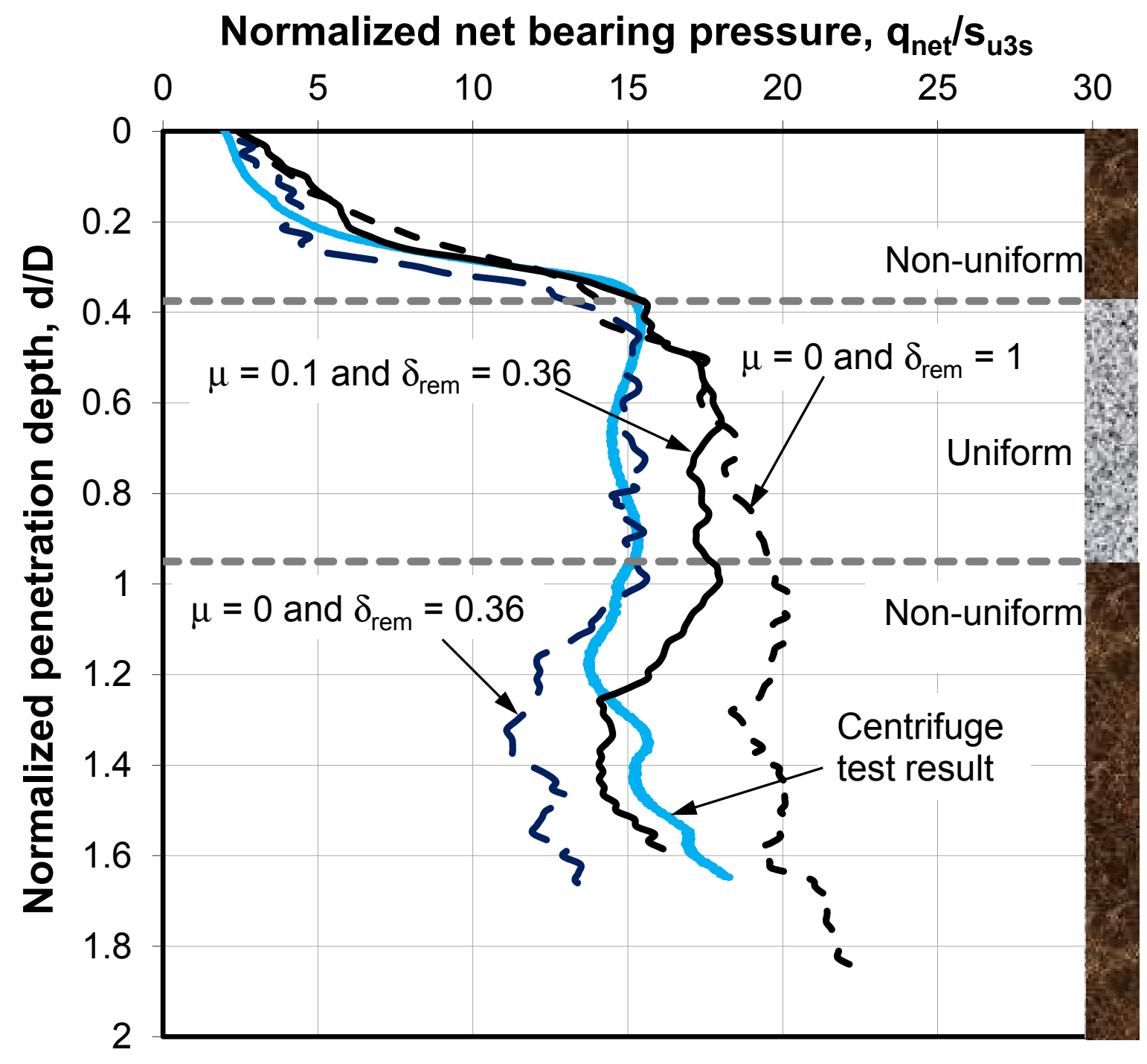




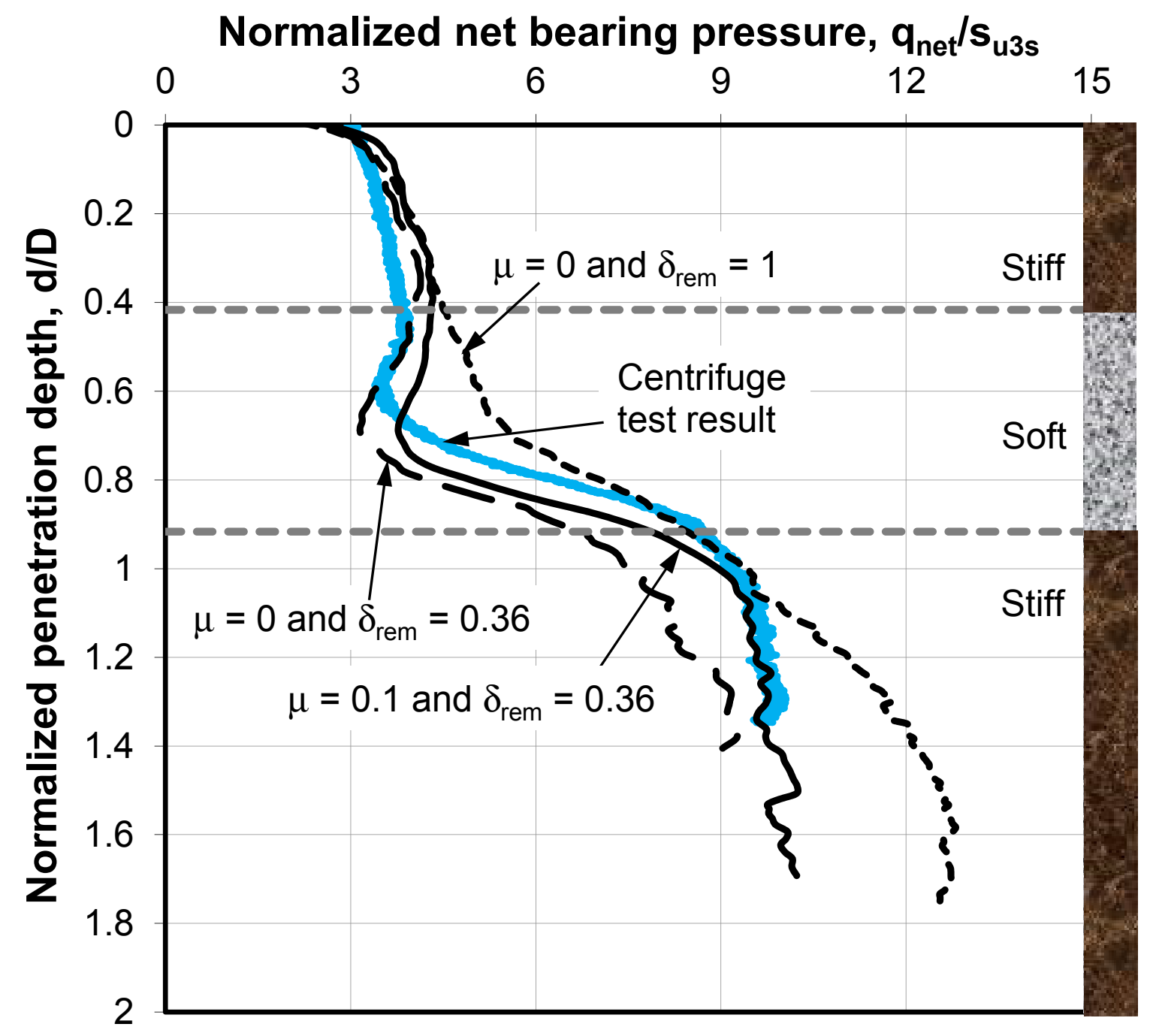




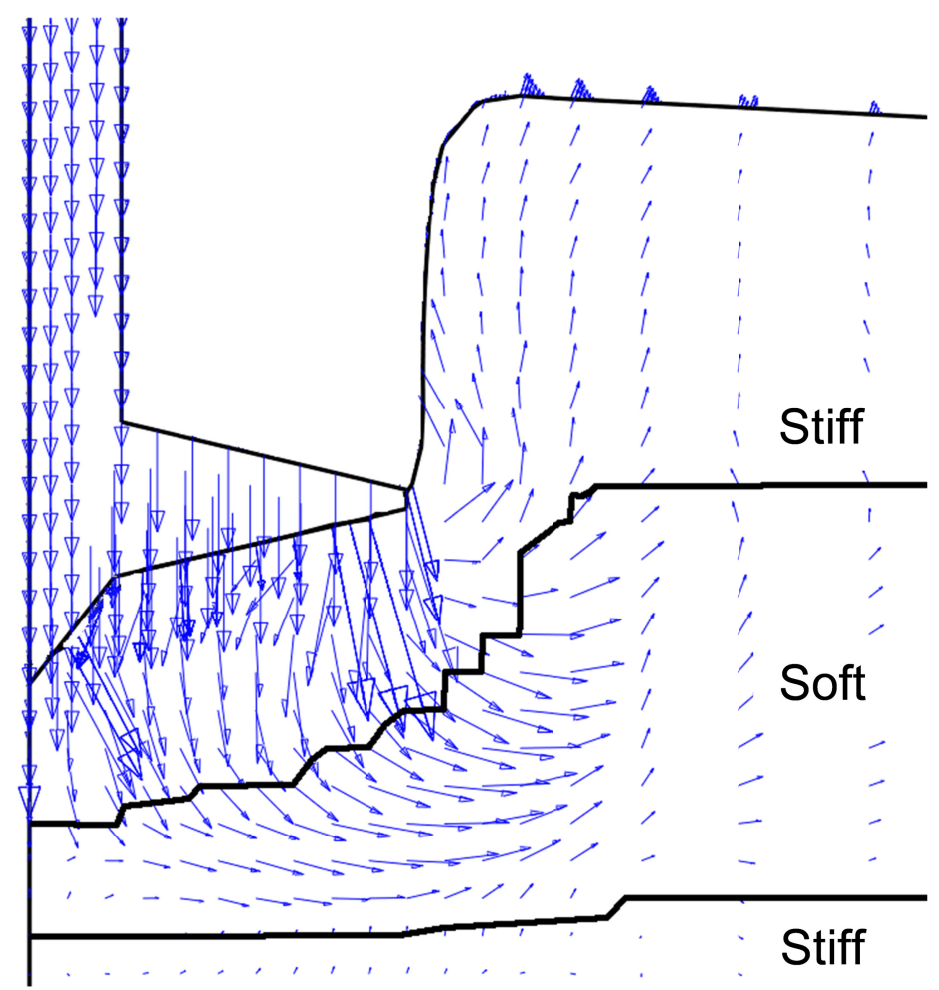




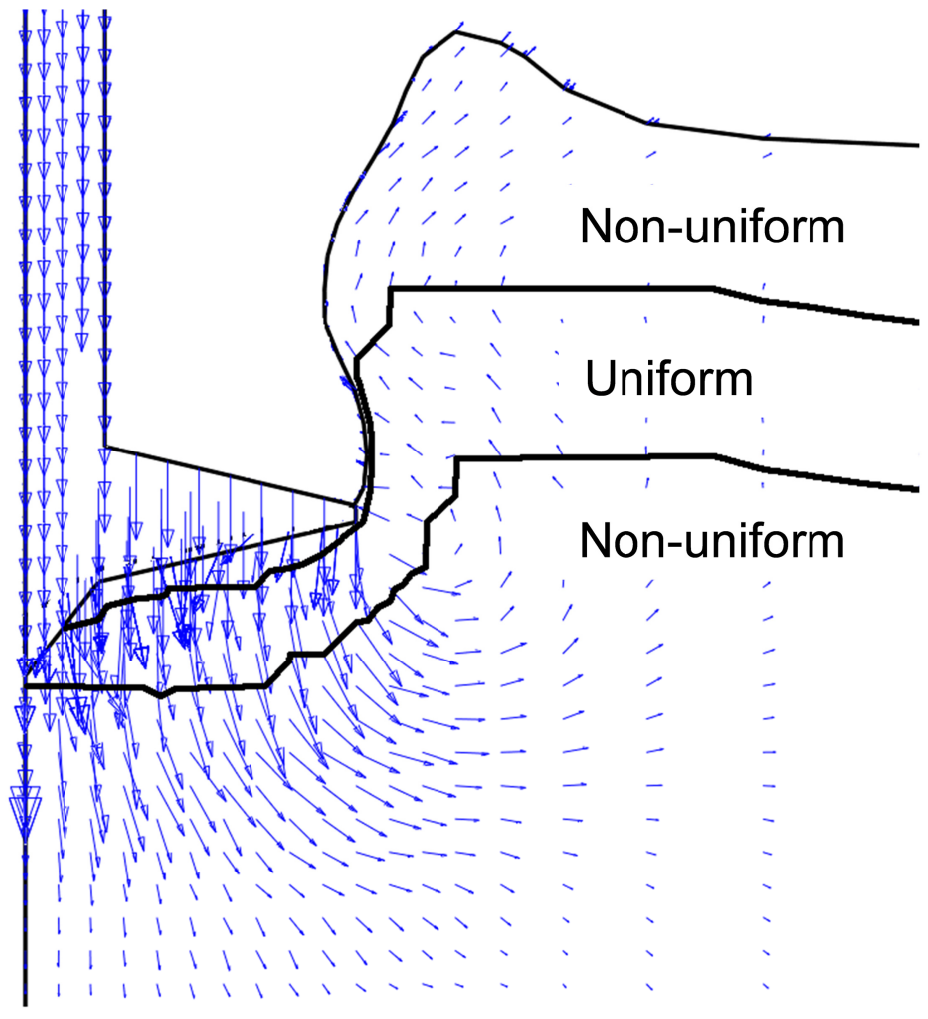




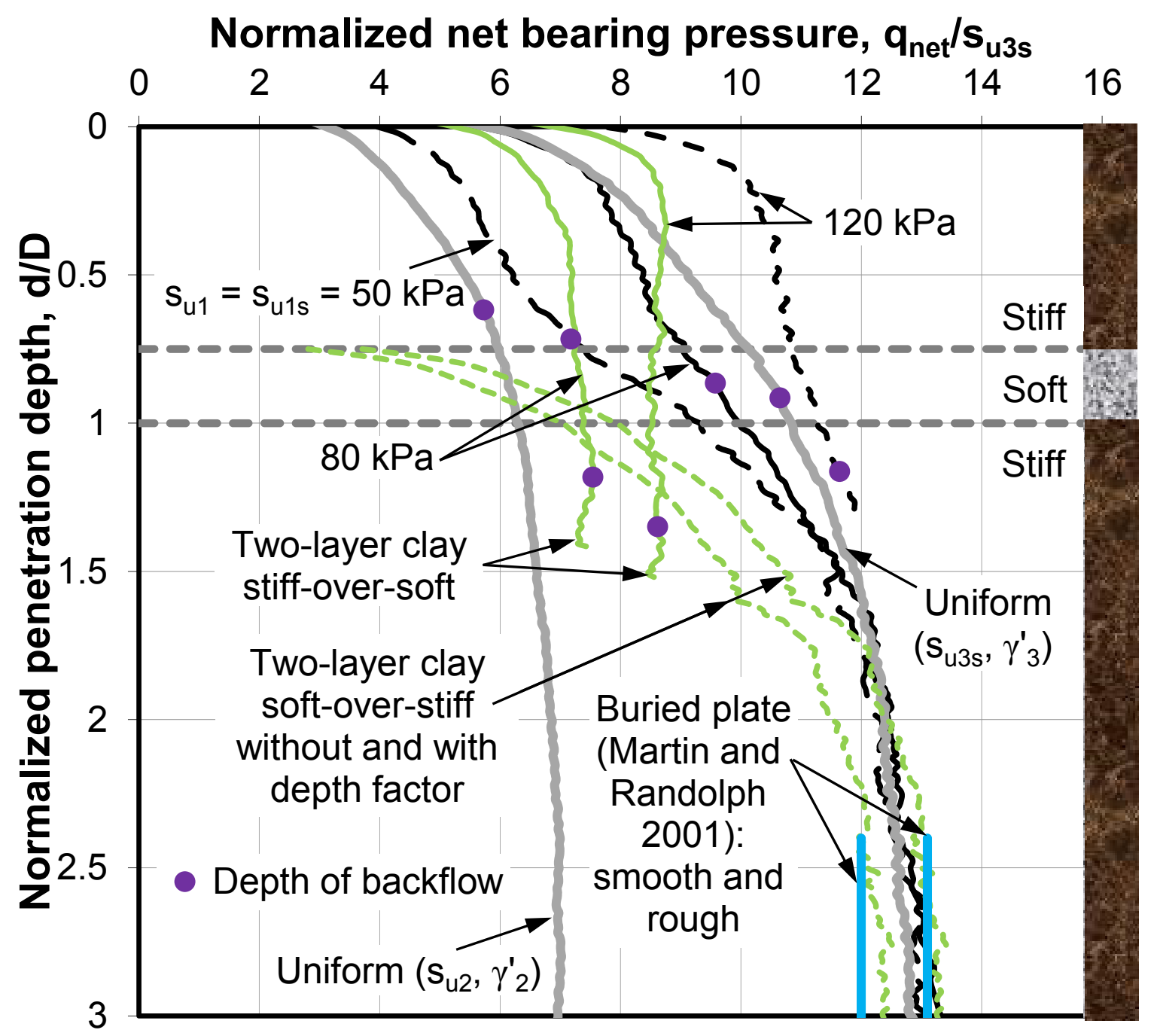




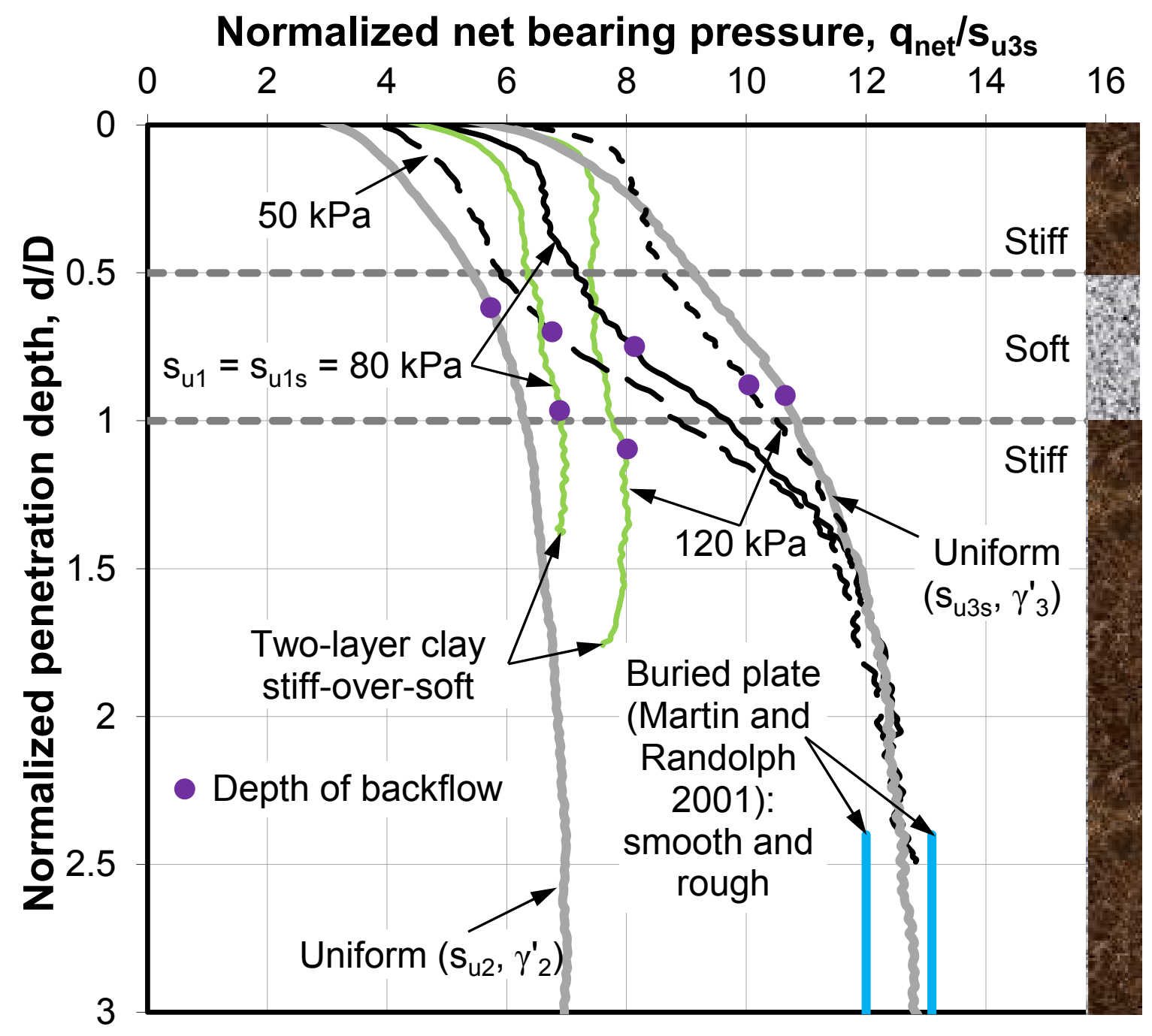




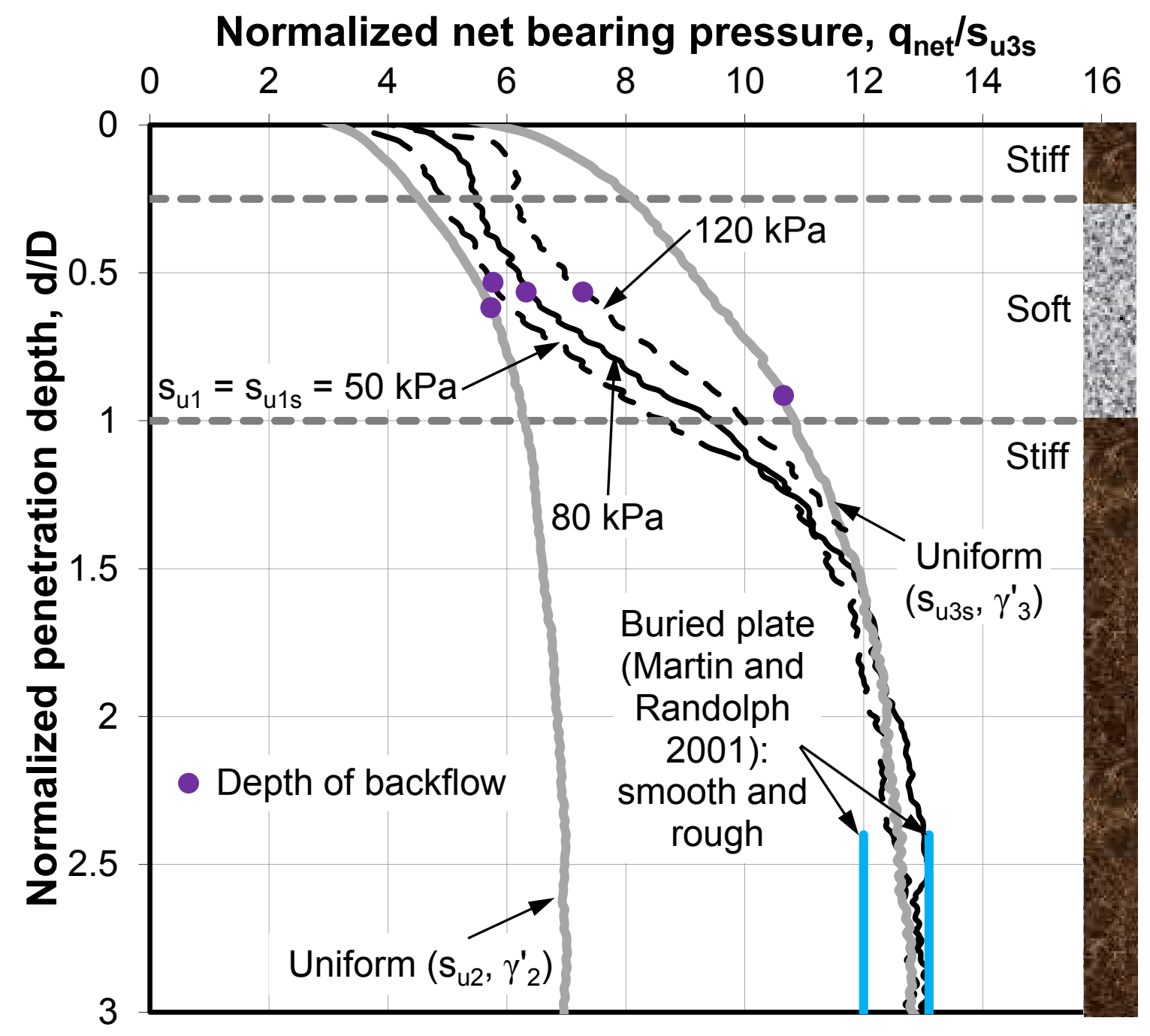




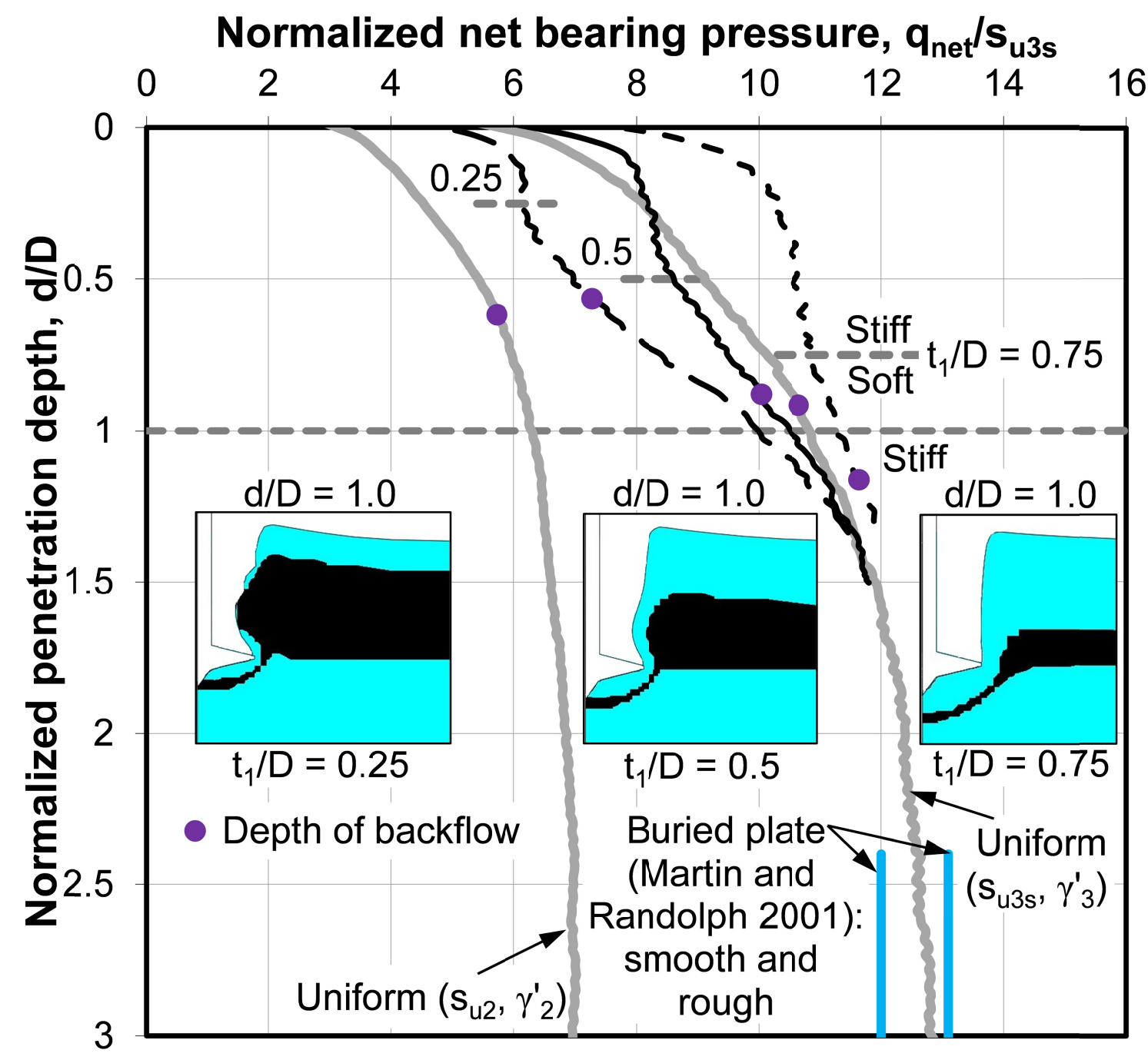




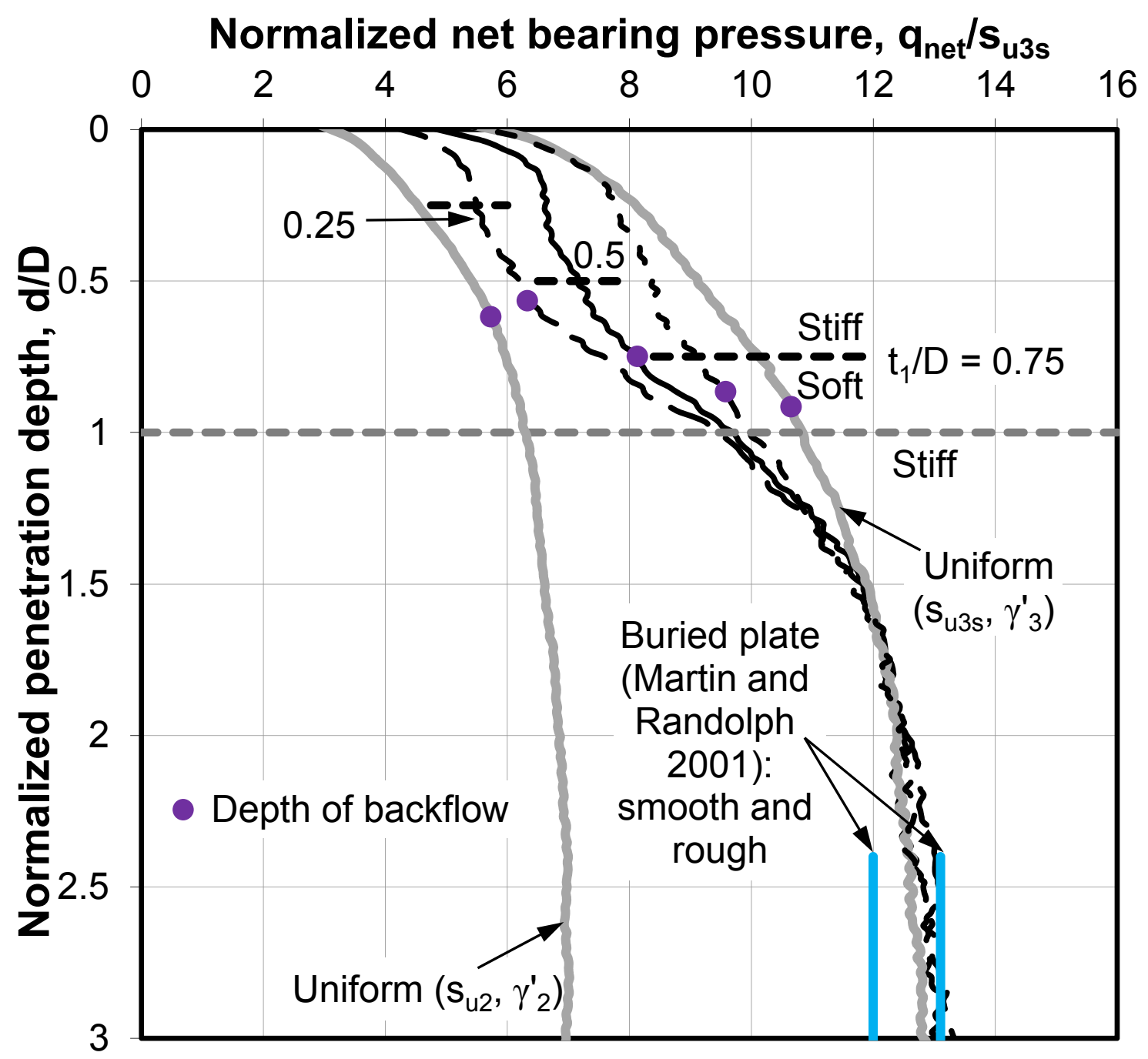




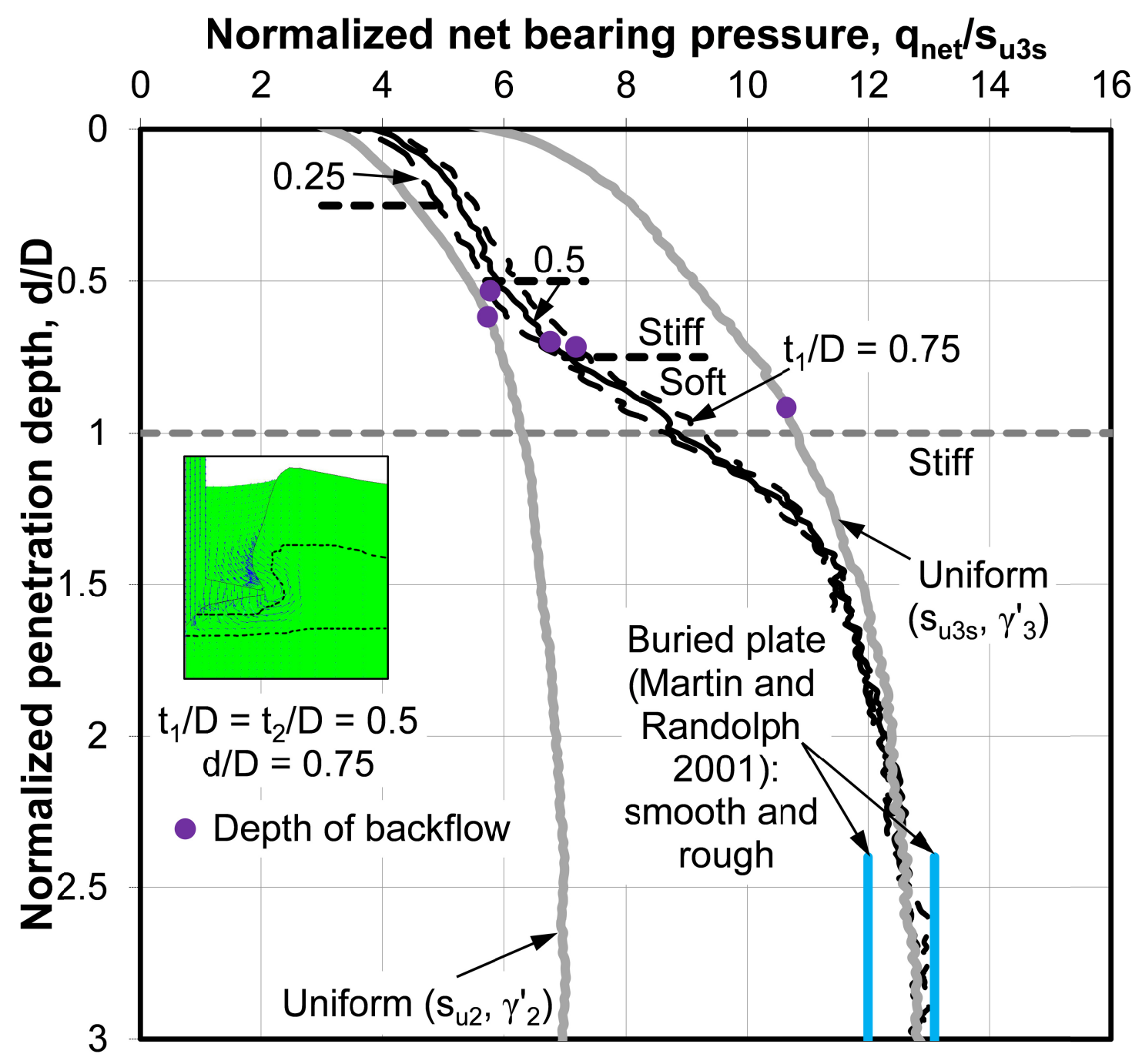




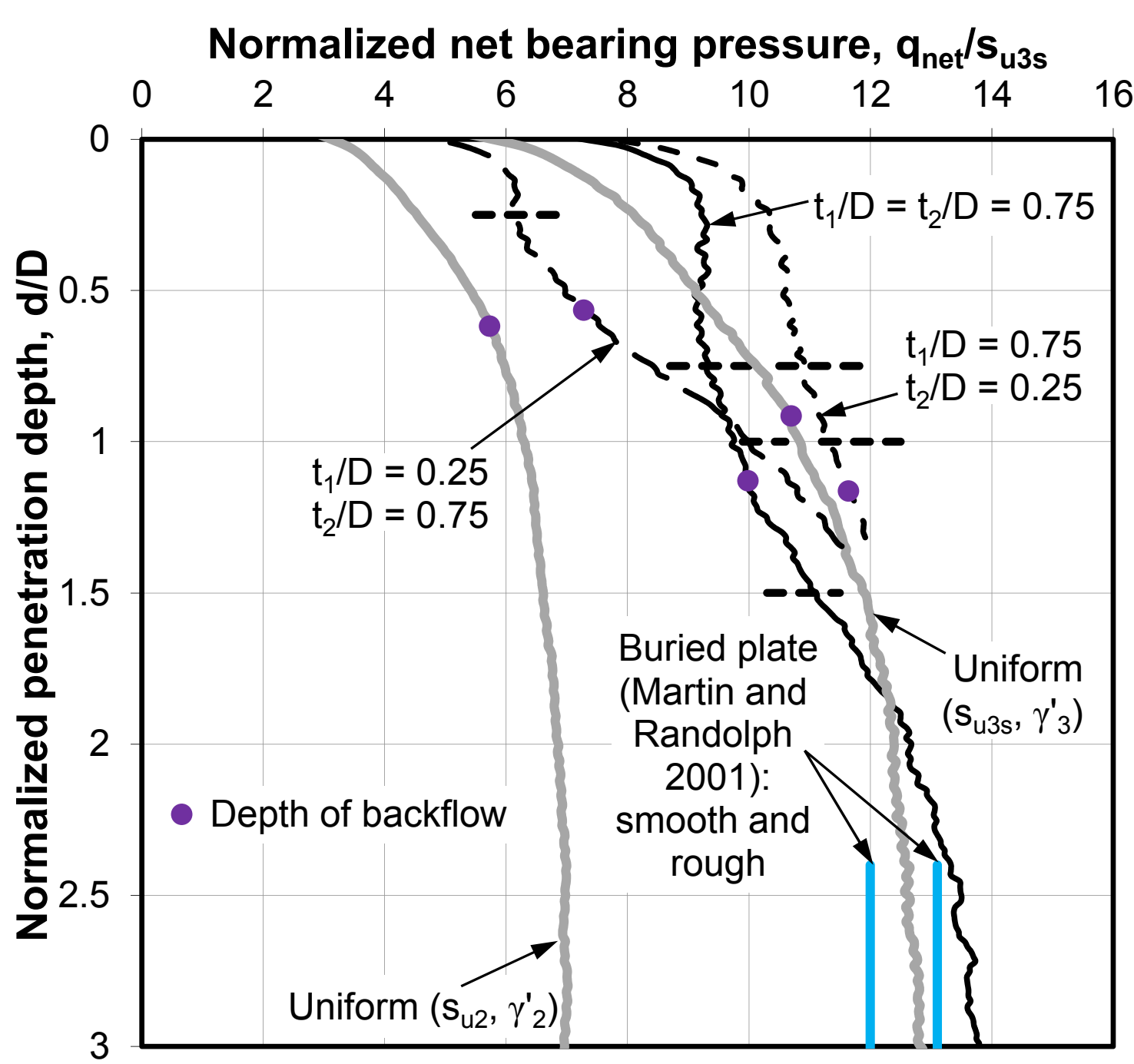




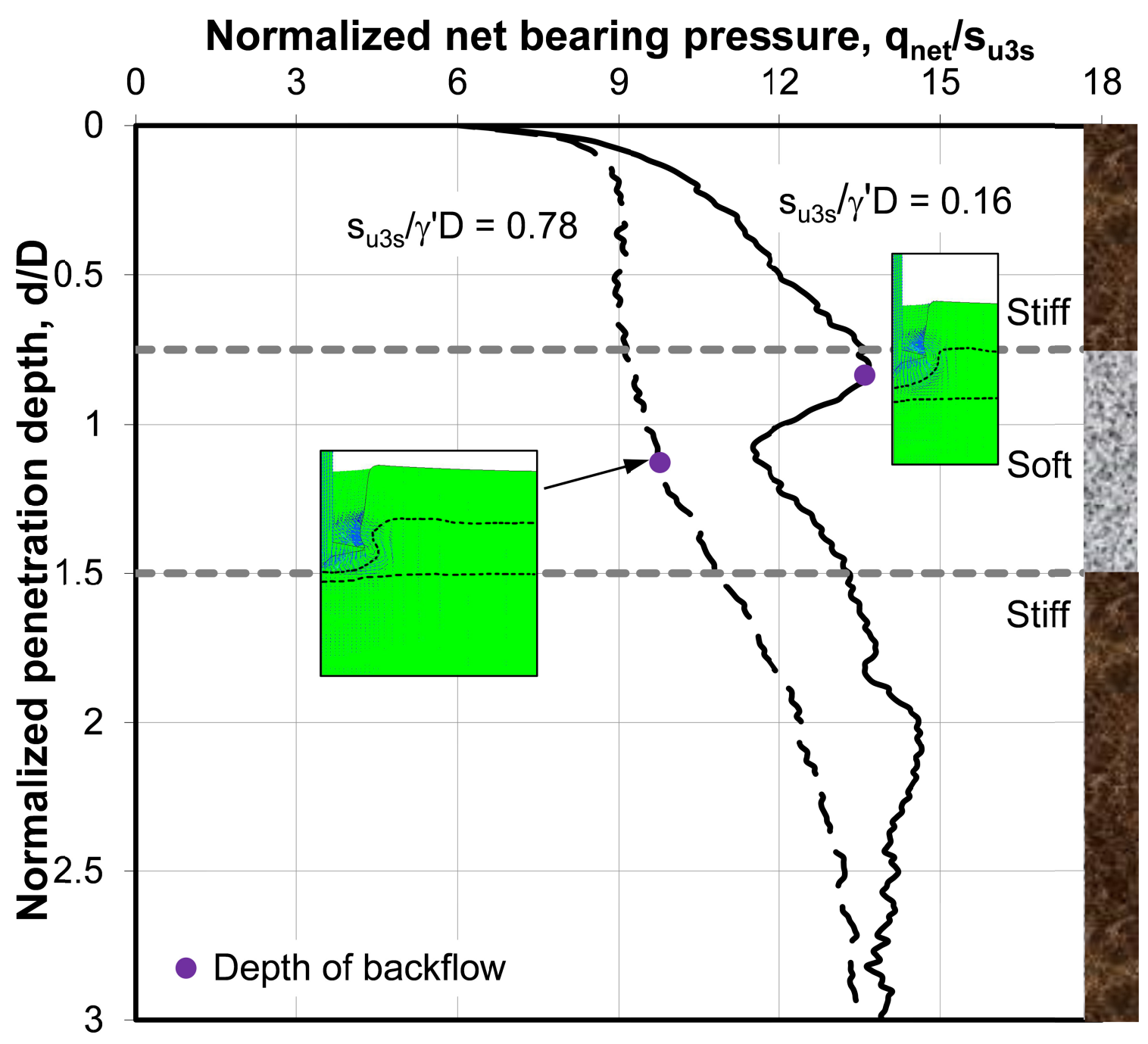




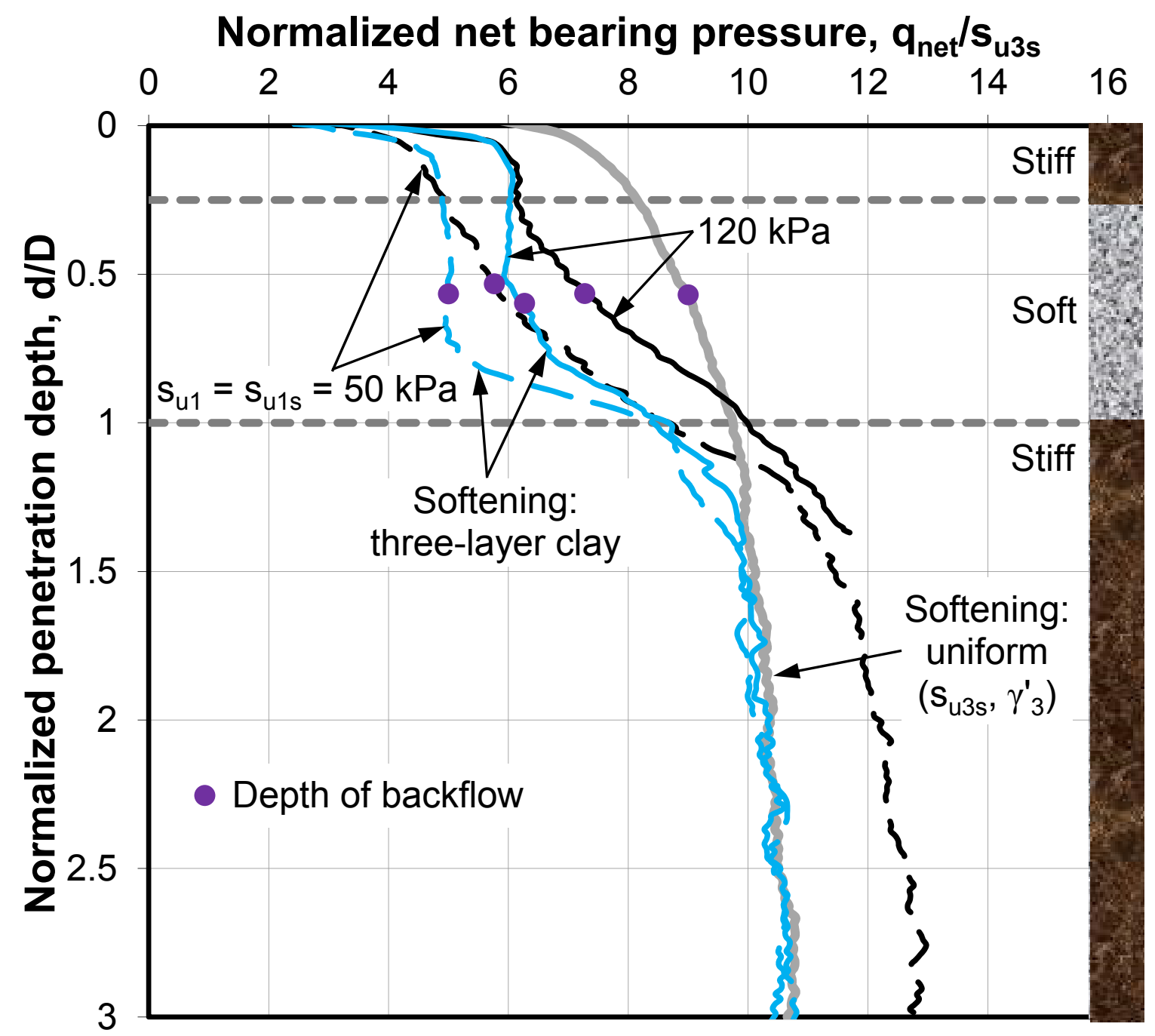




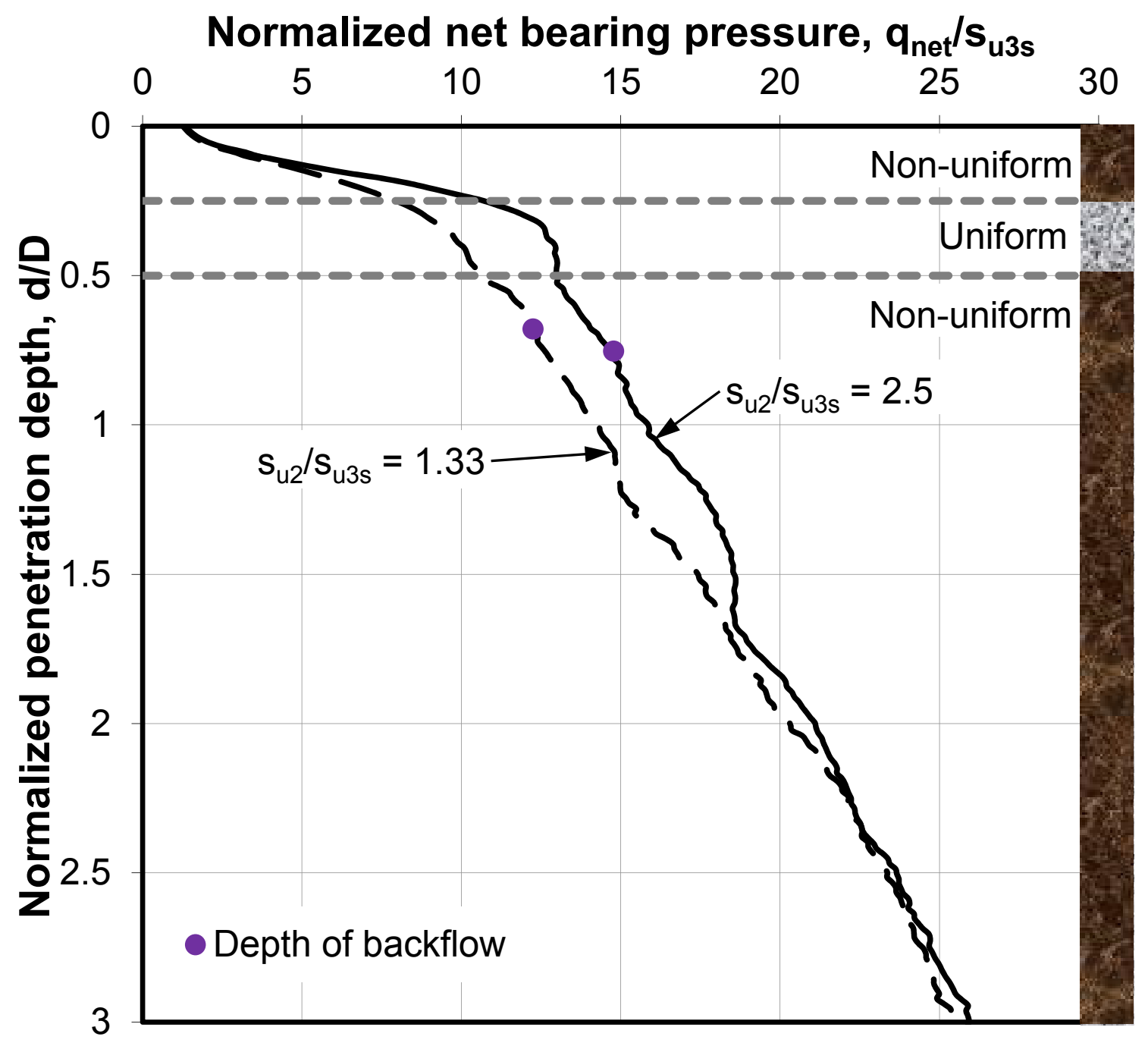




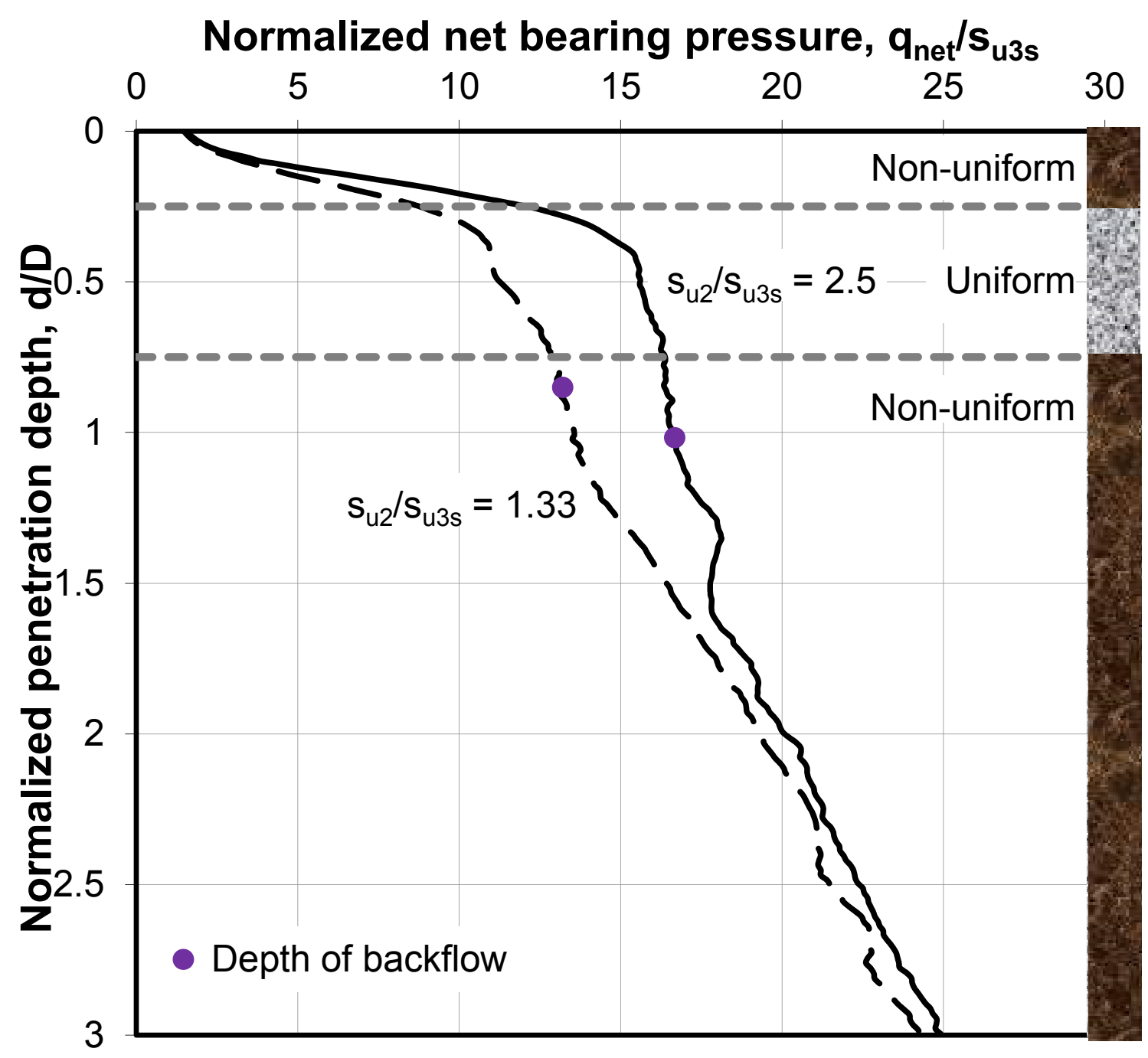




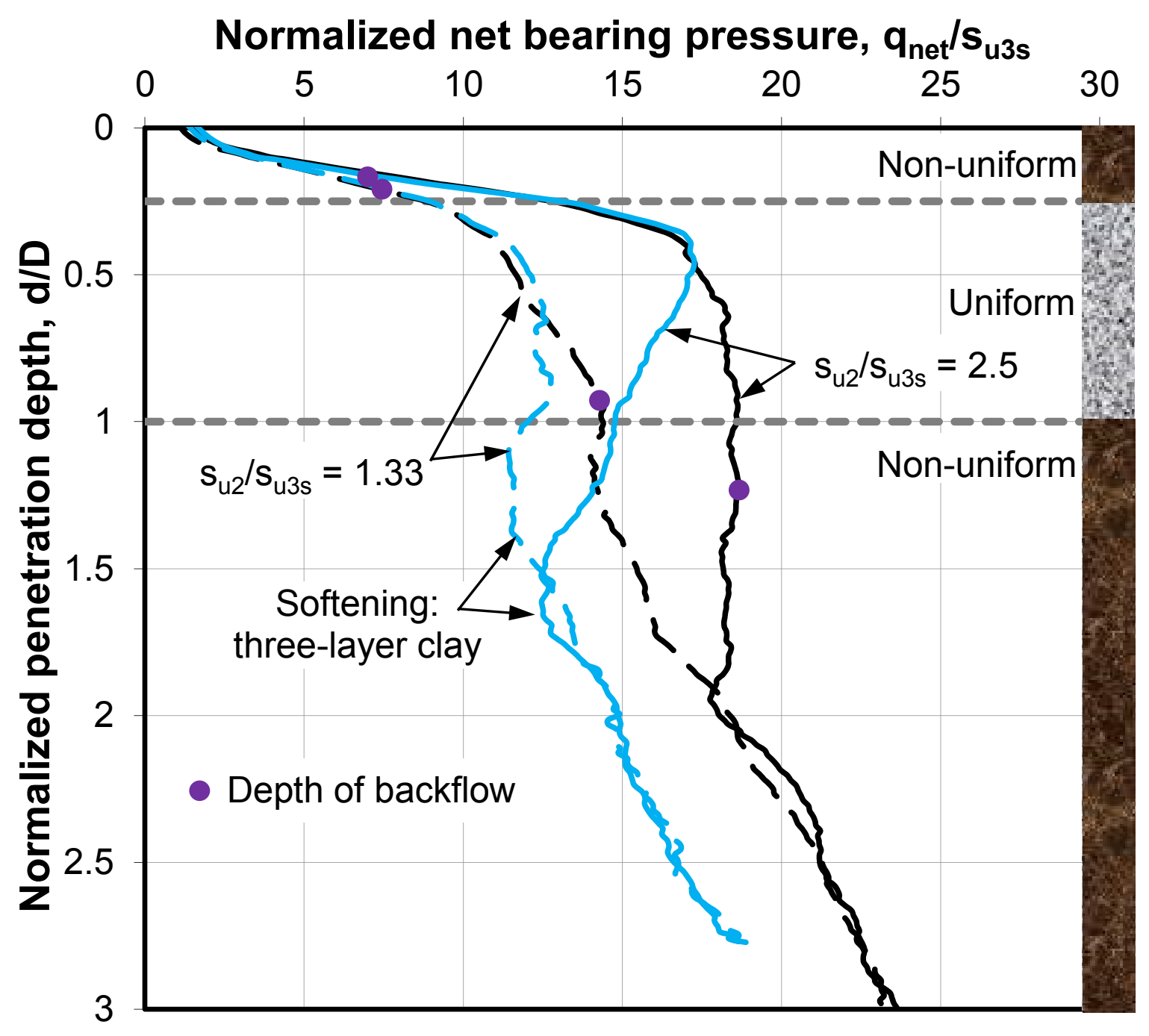




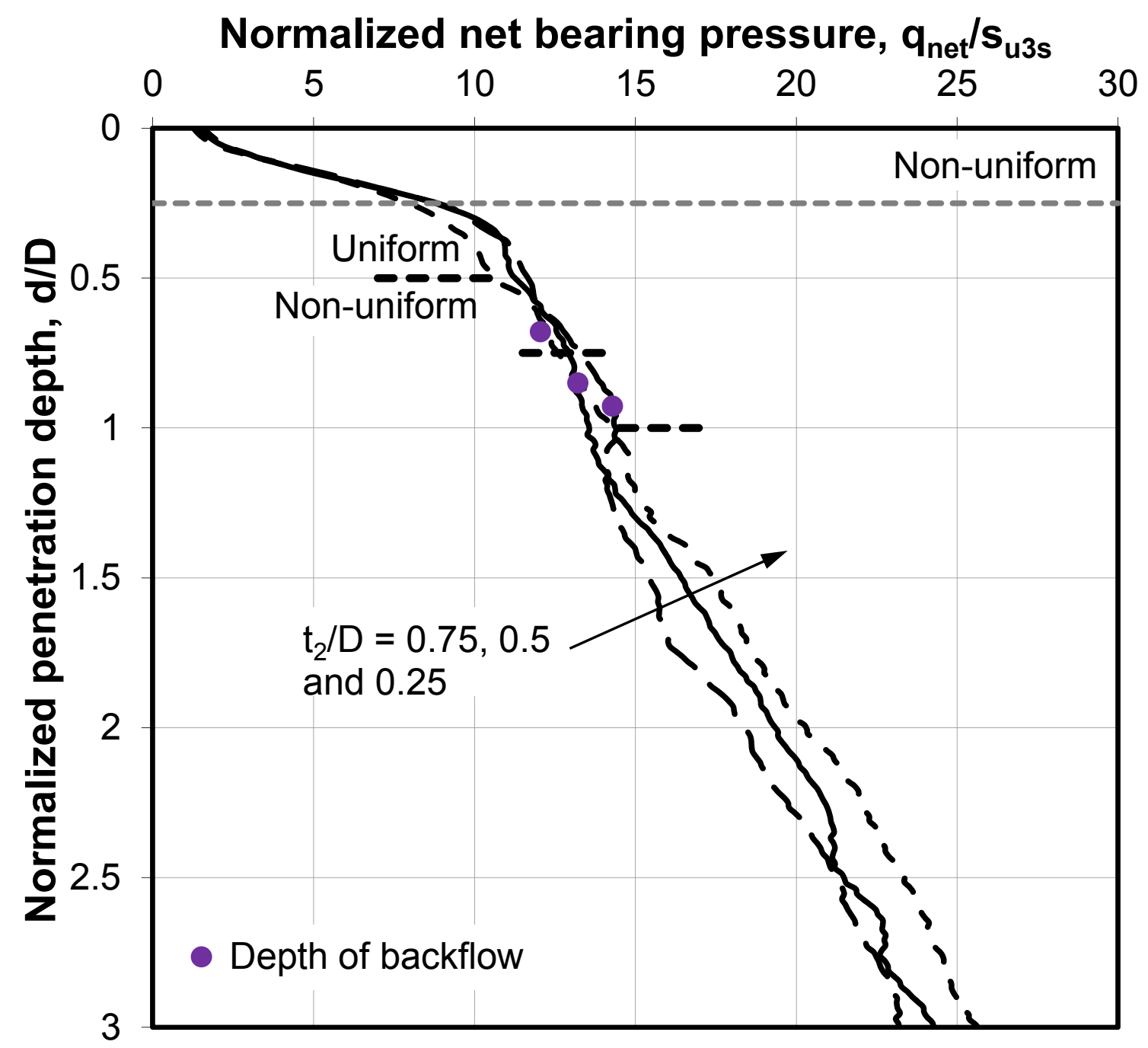




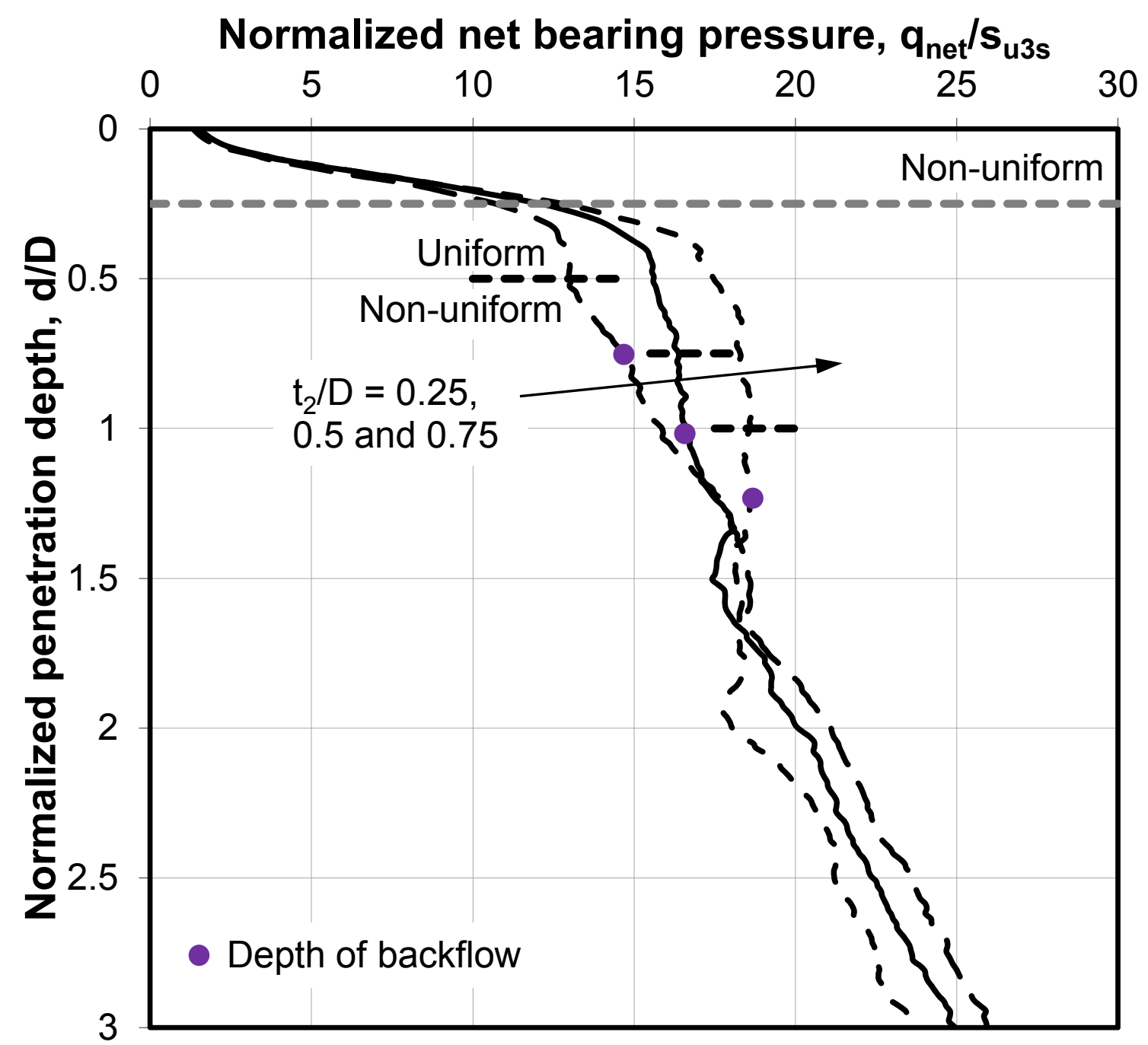




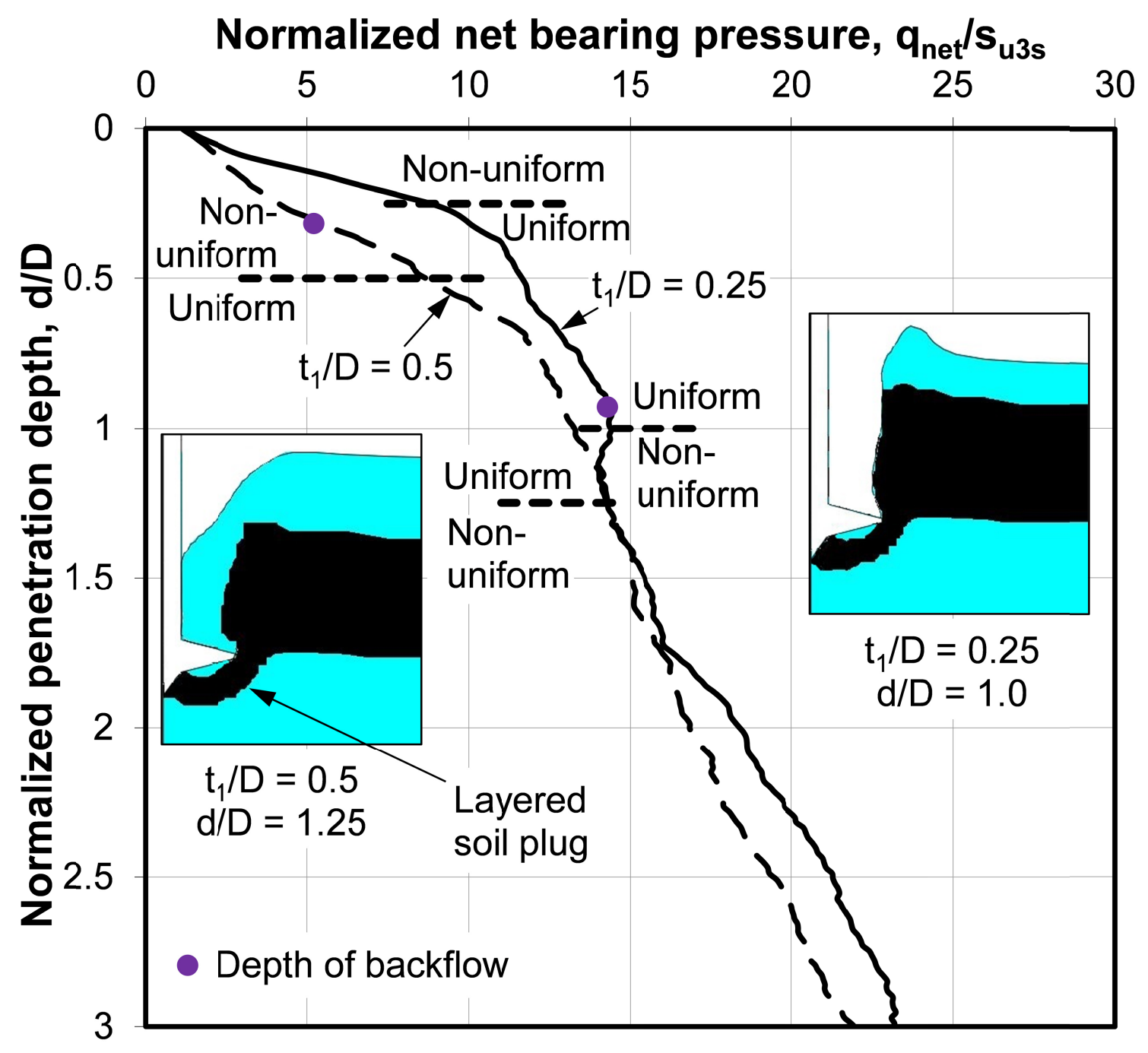




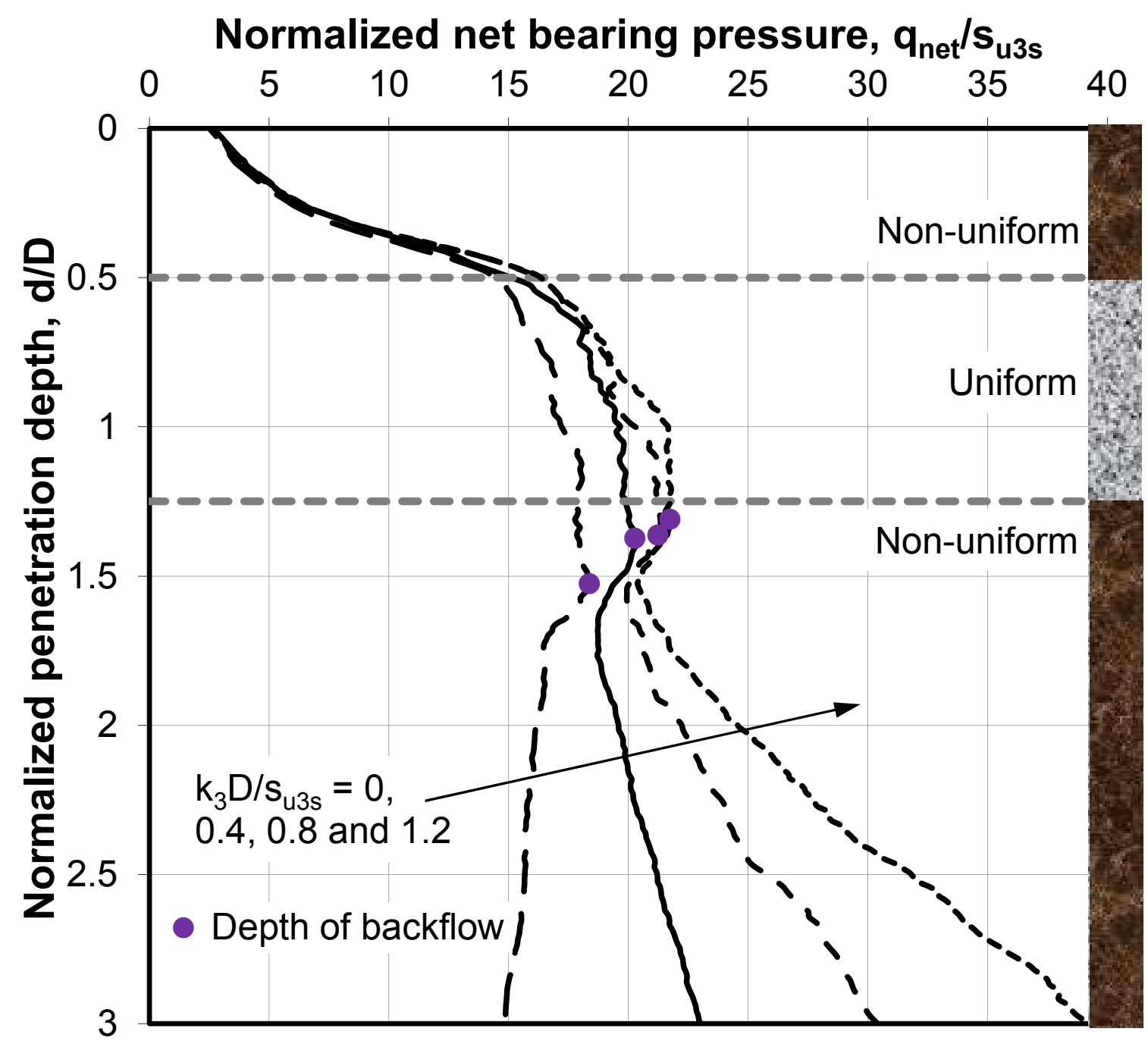

